\title{
COLONIZACIÓN FEUDAL Y ORGANIZACIÓN DEL TERRITORIO. MALLORCA, $1230-1350^{1}$
}

GABRIEL JOVER

Universidad de Gerona

RICARD SOTO

Universidad de Barcelona

\section{RESUMEN}

Tomando como ejemplo la isla de Mallorca, los autores muestran los diversos factores socioambientales, institucionales y económicos que modelaron la colonización feudal de la isla durante los siglos XIII y XIV. Asimismo, el estudio sugiere, a partir de la comparación de este caso con otros, que la fosilización de las estructuras agrarias bajomedievales introducía cierta «sen. da" (path dependence) que favorecía determinadas pautas de desarrollo en detrimento de otras.

\section{ABSTRACT}

Taking as an example the island of Mallorca, the authors identify the different socioenvironmental, institutional and economic factors that influenced the feudal colonization of this island in the thirteenth and fourteenth centuries. This study also suggests, by comparing this case with others, that the petrification of the late medieval agrarian structures introduced a sort of path

N. de E.: Fecha de recepción del artículo: junio, 2001.

Fecha de aprobación por el Consejo de Redacción: octubre, 2002.

${ }^{1}$ Este trabajo se ha realizado en el marco del proyecto Factores determinantes del desarrollo agrario en Cataluña: recursos naturales, organización del trabajo y cambio técnico (PB96-1157-C03-01) financiado por la DGICYT, dirigido por Ramón Garrabou y Enric Tello. Queremos agradecer a los miembros del equipo de investigación los comentarios y sugerencias que hicieron, y en particular a Enric Tello, Ramón Garrabou, Carolina Batet, Antonio López, Gaspar Feliu y Rosa Lluch. Asimismo queremos manifestar nuestro agradecimiento a los referees anónimos encargados por la redacción de la RHE, por las sugerencias y comentarios que nos han hecho. 
dependence which favoured certain patterns of development to the detriment of others.

\section{JEL Classification: N53, Q15}

\section{LA EXPANSIÓN DEL FEUDALISMO: PROBLEMAS Y FUENTES}

En general, dentro de la Europa en la que se expandió el feudalismo, convendría distinguir entre una zona nuclear, donde éste se formó de forma más o menos endógena, y como resultado de una evolución cronológicamente lenta, y otra zona, en la que el feudalismo se formó exógenamente, como consecuencia de su difusión hacia otras latitudes, entre las cuales se encontraría la Europa más meridional ${ }^{2}$. En estas regiones la expansión del feudalismo fue el resultado de pactos entre los magnates feudales, en los que, ex ante, se repartían el dominio territorial, la jurisdicción y las rentas sobre las nuevas tierras conquistadas. La «exportación» del feudalismo hacia el sur permitiría, sobre la base de los asentamientos agrarios y urbanos preexistentes, crear unas unidades de substracción de la renta territorialmente más homogéneas y compactas que las que se habían consolidado en les regiones septentrionales ${ }^{3}$. En las nuevas tierras conquistadas, sin embargo, el señorío habría de someter a las poblaciones indígenas - cuando no se trataba simplemente de su eliminación y sustitución por colonos procedentes del norte-, generalmente musulmanas, a un nuevo sistema de relaciones socioeconómicas y a unas nuevas modalidades de organización y de explotación de los espacios agrosilvopastorales ${ }^{4}$.

Los territorios que conformaban la Corona de Aragón ofrecen, precisamente, un campo privilegiado para comparar estos procesos de for-

${ }^{2}$ La bibliografía y las hipótesis sobre la formación del feudalismo en las áreas nucleares es muy abundante, basta recordar los trabajos de Wickham (1984, 2000), Bois (1989), Toubert (1973), Bonnassie $(1979,2000)$. Por lo que respecta a las hipótesis sobre las modalidades de expansión de este sistema la formulación más satisfactoria, en nuestra opinión, es la de Bartlett (1994). Este autor presenta Europa como una entidad expansionista, sobre el mundo celta, eslavo, griego, árabe y beréber, mediante la utilización generalizada de instrumentos de dominación específicos del feudalismo. Esta argumentación, sin embargo, no es inédita, ya que, según Torró (2000), se remonta a Lewis (1958), en cierta medida estas cuestiones también se las había planteado Bloch (1967).

${ }^{3}$ Sobre la formación y expansión del feudalismo en las regiones mediterráneas véanse los trabajos reunidos en Pastor et alia (1984), García de Cortázar (2000) y Barceló y Toubert (1998).

4 Sobre los problemas sociales y agrarios que planteaba la «domesticacion» de las cornunidades andalusies, y la sustitución de un régimen agrario por otro, véanse los trabajos recogidos en Barceló et alia (1988), Torró (1999) y Trillo (1999). 
mación y expansión del feudalismo, y las modalidades de colonización agraria que tuvieron lugar en los nuevos territorios anexionados ${ }^{5}$. Estudios recientes han mostrado cómo, a pesar de que las sociedades feudales de partida de la Cataluña del Noreste y las nuevas sociedades feudales establecidas en la Cataluña de Poniente (siglo XII), las islas Baleares (siglo XIII) y el País Valenciano (siglo xiII), compartían un mismo armazón jurídico, los regímenes agrarios que se desarrollaron bajo éste fueron muy diferentes ${ }^{6}$. Asimismo, estos feudalismos exógenos, si bien tenían ciertas similitudes en las instituciones que permitieron su estructuración y consolidación — cartas pueblas o repartimientos, franquicias, concentración de la población en villas, etc.- en cambio, los resultados de aquellos procesos ofrecen contrastes intensos, tanto en las modalidades de organización del territorio, como en las formas de distribución de la renta y la explotación del trabajo ${ }^{7}$.

Nuestro propósito es poner de relieve las dificultades con que toparon los procesos de colonización y feudalización que tuvieron lugar en la isla de Mallorca. Los señores feudales, después de la conquista, se encontraron con obstáculos ambientales y resistencias sociales al intentar imponer un nuevo modelo de sustracción (domesticación de unos agroecosistemas distintos, sometimiento de la población andalusí, poblamiento de los dominios con nuevos colonos, etc.), y, de otra parte, se vieron abocados a continuos conflictos interseñoriales (competencia por la renta y el poder), generados por el proceso de jerarquización económica y política de la pirámide feudal. El resultado de la colisión de las estrategias que articularon los diferentes grupos nobiliarios fue la cristalización, a principios del siglo XIV, de unas específicas formas de sustracción del excedente y de organización del espacio agrario ${ }^{8}$. Como han señalado diferentes autores, estas estructuras agrarias no determinaron el desarrollo histórico posterior, pero sí que introdujeron ámbitos donde la resilencia a los cambios sociales o económicos era mucho mayor que en otros. Ello haría más fácil que un tipo de desarrollo

s Sobre la formación y consolidación del feudalismo en la Cataluña del nordeste véanse los trabajos de Bonnassie (1984, 2000), Bisson (1984), Feliu (1999a, 1999b) y Salrach (1999).

${ }^{6}$ La enfiteusis y los usatges de Barcelona codificados por los notarios y juristas catalanes a lo largo de los siglos XII y XIII (Freedman, 1988; Pons Guri, 1985/6), constituyeron dos instrumentos jurídicos importantes en el proceso de feudalización de los nuevos territorios (Soto y Batet, 1997; Portella, 1985/6, 1998).

7 Sobre su expansión hacia el poniente catalăn, Batet (1996, 2000) y Virgili (2001). Para la conquista y colonización en el siglo XIII del País Valenciano, Guinot (1997), Furió (1997a) y Torró (1999, 2000), y de Mallorca, Soto (1991, 1992, 1996).

${ }^{8}$ Guichard (1976), Barceló $(1984,1989,1995)$ Torró (1999) y Jover y Soto (en prensa). 
agrario encontrara mayores facilidades en determinados nichos socioeconómicos que en otros 9 .

Para estudiar estos procesos utilizaremos fuentes de tres tipos: en primer lugar, los numerosos estudios dedicados a esta etapa y la documentación publicada por los cronistas e historiadores locales; en segundo lugar, la rica información que proporcionan la serie de documentos de la Escribanía de Cartas Reales (ECR), en la cual se anotaban los cambios en los dominios, los contratos agrarios y las rentas de los dominios reales durante el siglo xil, y, finalmente, la documentación notarial, fundamentalmente los inventarios de los dominios señoriales de la primera mitad del siglo XIV.

\section{LOS REPARTIMIENTOS FEUDALES EN MALLORCA}

Los pactos entre los magnates feudales catalanes en los años inmediatamente anteriores y posteriores a la conquista (1228-1232), definieron a grandes rasgos cómo se habían de distribuir el territorio, las rentas y la jurisdicción en la isla de Mallorca. Un primer repartimiento entre el monarca y los cuatro grandes magnates -el obispo de Barcelona, el conde del Rosellón, el conde de Ampurias y Gastón de Montcada- dividió la isla en cinco grandes porciones. Cada una de éstas estaba encabezada por un magnate bajo el cual se agrupaban nobles de rango inferior, instituciones religiosas e instituciones urbanas que participaron en la partida de cada uno de los magnates. El repartimiento dentro de cada una de estas porciones fue muy diferente, en función de las relaciones feudovasalláticas de los miembros o instituciones que las integraban. En todo caso, estos primeros repartimientos entre los magnates y los magnates porcioneros (obispo de Girona, Gilabert de Centelles, Monasterio de Sant Feliu de Guíxols, R. de Sant Martí, etc.) crearon un primer estrato nobiliario caracterizado por la posesión de grandes feudos, denominados en la documentación de la época, y también en la posterior, baronías. Estos grandes dominios señoriales poseían la jurisdicción civil y criminal, el dominio directo, monopolios y el diezmo sobre los respectivos territorios ${ }^{10}$. Para simplificar, a los miembros de este estrato nobiliario, integrado por la alta nobleza

9 Bloch (1967, [1931]1978), Comninel (2000) y Bates (2000).

${ }^{10}$ La bibliografía sobre los repartimientos feudales en la isla es muy extensa, ver una sintesis en Soto $(1990,1996)$, Cateura (1997, pp. 57-141), Portella (1994, pp. 427-441) y Jover y Soto (1997). 
que generalmente residía fuera de la isla, lo denominaremos a lo largo del estudio barones o magnates ${ }^{11}$.

El monarca y los barones repartieron a su vez una parte importante de sus dominios entre los miembros de sus séquitos. Esta segunda oleada de repartimientos tendría tres modalidades diferentes de cesión del dominio. Por un lado, el monarca y los barones infeudaron o donaron señoríos, denominados en Mallorca caballerías, a los miembros de la pequeña nobleza (caballeros o donceles) que formaban parte de su hueste o séquito ${ }^{12}$. Las caballerías en general estaban dotadas con la jurisdicción baja, aunque en algunos casos poseyeron la jurisdicción criminal, el dominio directo y el diezmo sobre un territorio, generalmente compacto, que tenía una extensión de entre unas 230 hasta más de 1.000 hectáreas. Con estos procesos de infeudación se crearían más de un centenar de pequeños feudos, muy desigualmente repartidos en los diferentes dominios de los magnates. Los caballeros que poseían estos dominios constituirían un segundo estrato nobiliario, la pequeña nobleza feudal que residiría en la isla y ocuparía los cargos políticos y militares más importantes del reino (castellanos, gobernadores de la isla, cargos en la justicia real, procuradores del patrimonio real, etc.). Por otro lado, una parte importante de los dominios reales y baroniales fueron cedidos en 'alodio franco' o dominio directo a caballeros, ciudadanos $\mathrm{u}$ otros ricos hombres o instituciones que formaban parte de las porciones de los magnates ${ }^{13}$. Finalmente, la mayor parte del territorio poseído por los barones, y una parte importante del que poseían las caballerías y también de los alodios, fue establecido en enfiteusis a los colonos

${ }^{11}$ En otros lugares (Soto, 1990; Montaner, 1986), sin embargo, se ha insistido en la necesidad de matizar la jerarquización que se produjo dentro del grupo de la alta nobleza, distinguiendo entre los magnates, propiamente (rey, Nunó Sanç, el conde de Ampurias, Gastó de Béarne y el obispo de Barcelona) y sus porcioneros. De todos modos, la gran nobleza constituía un bloque relativamente homogéneo, perfectamente diferenciable de la pequeña nobleza y del conjunto de tenencias alodiales y, posteriormente, enfiteutas (Soto, 1990, p. 12).

12 Sobre este tipo de señoríos véase Cateura (1988, 1997), Montaner (1986, pp. 42-64), Portella (1994) y Jover y Soto (1997, pp. 217-275). Sobre los procesos de infeudación, Soto (1990, 1991); en la porción del conde Nunó Sanç, en Cateura (1988, pp. 99-114), Mut y Rosselló (1993) y también Soto (1994, pp. 347-365); y el estudio de los repartimientos e infeudaciones en la porción del obispo de Girona realizado por Pérez (1994, pp. 69-96). La caballería era un tipo de feudo común en los procesos de expansión feudal que podemos encontrar en Cataluña [Bisson, 1984, pp. 71-72; Bonnassie: 1979/81 (II), pp. 195-204; 1984, pp. 26-27] o en Sicilia y Portugal (Bresc, 1997, pp. 180-183).

${ }_{13}$ Algunos de estos dominios directos, posteriormente, se convirtieron en feudos, cuando el monarca a final del siglo xII o a principio del xrv, les concedió la jurisdicción baja y el diezmo sobre aquellos territorios, véase Soto (1991) y Montaner (1986, p. 61). 
que acompañaban a la hueste, o que se añadieron en las primeras oleadas migratorias. En general, las tierras fueron establecidas en grandes unidades, tal vez, originariamente, siguiendo la estructura andalusí del parcelario. Los beneficiarios de estas grandes explotaciones, que adoptaron los nombres preexistentes (de origen árabe) de alquería y rafal, subestablecieron una parte de estas tierras a otros colonos, y algunos de éstos volvieron a establecer parte de las tierras a otros campesinos ${ }^{14}$.

A lo largo de la segunda mitad del siglo XIII y durante el primer cuarto del siglo XIv, los repartimientos originales se modificaron sustancialmente. Ello fue consecuencia de los conflictos internobiliarios derivados del proceso de jerarquización de la pirámide feudal, léase de las luchas entre el monarca, la Iglesia de Mallorca y los señores feudales, laicos y eclesiásticos, por la posesión de las rentas, especialmente del diezmo, y la distribución del poder jurisdiccional ${ }^{15}$. Los resultados de aquellas pugnas pueden sintetizarse como sigue. A lo largo de la segunda mitad del siglo XIII el monarca incorporó la mayoría de baronías laicas (la porción de Nunó Sanç, la de Gastó de Bearn, etc.), en algunos casos estas incorporaciones fueron resultado de las dificultades financieras de los condes y barones que voluntariamente vendieron sus dominios al monarca para saldar las deudas acumuladas; en otros, en cambio, fue la presión directa del rey la que obligaría a los magnates a alienar su patrimonio. De este modo, en la segunda década del siglo xIv el rey se había convertido en el magnate feudal más importante de la isla, de manera que los únicos magnates que quedaron con dominios importantes eran instituciones religiosas (Obispos de Barcelona y Girona, Paborde de Tarragona, Monasterios y conventos, etcétera).

En segundo lugar, el monarca había concedido a los pobladores de sus dominios ciertas franquicias que prohibían taxativamente el sometimiento de los colonos a la servidumbre o a los malos usos ${ }^{16}$. Estos privilegios, al principio, únicamente se circunscribían a los dominios reales,

${ }^{14}$ Los niveles de fragmentación de estas alquerías, como veremos posteriormente, fueron muy desiguales. En la Mallorca occidental (Raïguer y valles de la Sierra de Tramontana), las alquerías se parcelaron rápidamente en explotaciones de tamaño relativamente pequeño, mientras que en el centro y este de la isla se mantuvieron como grandes unidades agrarias hasta el siglo $\mathrm{xV}$, en algunos casos el proceso fue inverso, pues tendieron a la concentración en unidades mayores, antes que a la fragmentación. Véase Soto (1990, 1991), Portella (1985/6, pp. 331-343), Rodríguez (1985/6, pp. 371-387; 1994, pp. 367-403).

15 Cateura (1997, pp. 59-78) y Jover y Soto (1997, pp. 225-231).

16 Salvà (1970, p. 388) señalaba como característica de la «Carta de franquesa» la exención de malos usos y dependencia feudal a semejanza de todas las concedidas a villas de señorío reales en su análisis de ésta, haciéndose eco de la frase de Ramón Muntaner 
y dentro de ellos a las caballerias o pequeños dominios feudales que se hubieran infeudado ${ }^{17}$. Pero, desde las décadas centrales del siglo XIII el monarca, probablemente apoyado por los colonos y las villas de la isla, impulsó la generalización de estas franquicias reales al conjunto de los dominios señoriales ${ }^{18}$. Esta ofensiva real se encontró con una enconada resistencia de los señores poseedores de baronías y caballerías, que fue vencida progresivamente mediante la incorporación de las baronías, que extendía automáticamente los privilegios reales a los pobladores de los dominios incorporados, o bien mediante presiones políticas ${ }^{19}$. La extensión

«e poblà la dita illa e ciutat ab majors franquees e llibertats que ciutat sia al món» (Ibid., p. 387), en lo que fue seguido por otros autores, entre otros Santamaría (1990, pp. 31-48). Más adelante, sin embargo, matiza que, sin mencionarlos expresamente, la Carta de Franqueza contiene en su espíritu la derogación o, más exactamente, la exclusión, de los malos usos (Ibid., p. 402).

17 En cambio, en los establecimientos realizados en los dominios de los barones que procedían de la Cataluña del Noreste aparecían fórmulas muy semejantes a las que podemos encontrar en los dominios continentales donde predominaba la servidumbre. En Mallorca se han encontrado fórmulas contractuales de establecimiento que incluyen la condición del «afocament», desde los primeros tiempos de la repoblación en los dominios de Nunó Sanç de Bunyola y Valldemossa y, sobre todo, en la porción de Guilabert de Cruilles, en Banyalbufar (Soto, 1991, docs. 19, 56, 75, 319, 321, 322, 325, 376, 533, 577, 581, 582 y 620). Aunque también se han encontrado algunos ejemplos en Felanitx (Soto, 1991, doc. 56). La pervivencia de estas formas primarias de servitud o malos usos en la isla también quedaron reflejadas en el acta de venta de los dominios de Bernat de Santa Eugènia a su hermano Guillem de Montgrí del año 1268, entre los derechos señoriales de este magnate se mencionaban «cuguciis, exorquiis, intestiis» y la "redemcionibus bominum et feminarum et prelaticis» (López Bonet, 1998, p. 101).

${ }^{18}$ En 1268 el monarca apoyaba a los campesinos de las villas en sus litigios contra los señores feudales en las disputas sobre límites y usos de los comunales (Cateura, 1985, p. 74). Esto parece claro en villas como Felanitx, donde el crecimiento del núcleo urbano fue posterior a la intervención real del 1300 , y a lo largo de la primera mitad del siglo XIV se produjeron numerosas disputas entre el señor de la caballería y los vecinos de la villa. También sucede algo parecido en la parroquia de Campanet, en la que se varió el emplazamiento del núcleo urbano para situarlo dentro de la jurisdicción real (Mas, 1994, pp. 387-394; Bernat y Serra, 1997). Estos conflictos deben leerse también en el contexto del movimiento campesino que demandaba la institucionalización de los concejos rurales (universitats), finalmente conseguida por el monarca en el año 1315. Éste puso en manos de estos concejos el cargo de baile, o sea, el representante de la jurisdicción real en el término de la villa (Planas, 1995; Cateura, 1982a, pp. 150-151, 1999).

${ }^{19}$ En el estudio de Antonio Planas sobre la formación de las villas y la consolidación de los bailes reales, se nos recuerda que: «Sólo en 1251, los bailes de los señores jurisdiccionales fueron obligados a jurar las franquicias, y todavía en 1302 los Templarios se negaban a jurarlas y se resistían a cumplir sus prescripciones» (Planas, 1995, p. 22). De otra parte, el rey obligaria a los barones a compartir la jurisdicción de sus baronías con el monarca. En algunos casos el monarca hizo valer su fuerza política y militar para imponer a sus bailes, como en los dominios que el Paborde de Tarragona tenía en Ibiza (Urgell, 1990, pp. 15-32). En otros casos esta preeminencia se consiguió mediante acuerdos y com- 
de estos privilegios al conjunto de los pobladores limitaba los derechos señoriales sobre las personas a los derivados de su posesión de bienes en el dominio feudal (generalmente la obligación de cabrevar los bienes que poseían, y el pago de censos, laudemios, tascas, diezmos y otras cargas feudales), pero no tenían ningún tipo de derecho sobre las personas físicas -servidumbres o malos usos- o su movilidad. Ello significaba que en las reservas señoriales no podría utilizarse mano de obra servil, así que los señores se vieron obligados a utilizar otro tipo de trabajo forzado, la esclavitud, o bien mano de obra asalariada ${ }^{20}$.

En tercer lugar, de estos conflictos internobiliarios la Iglesia de Mallorca, el obispo y el Capítulo de la Catedral salió notablemente fortalecida. Esta institución, según los pactos de 1230, debía ser dotada por todos los barones y señores feudales que participaron en la conquista con un 10 por 100 de sus bienes, generalmente en forma de alodios, alquerías en dominio útil, y en algunos casos con caballerías. Estas donaciones suponían la constitución de un patrimonio importante, pero muy fragmentado y difícil de gestionar, especialmente en las etapas iniciales de la posconquista ${ }^{21}$. Por ello, ya desde el decenio de 1240 el Obispo de la isla y el Capítulo Catedralicio ejercieron presiones crecientes sobre los barones y caballeros, para incorporar la totalidad del diezmo a su patrimonio ${ }^{22}$. Los conflictos y pleitos comenzaron en la década de 1240 y se alargaron hasta 1315 , cuando el monarca y el resto de magnates aceptaron conceder la mitad de todas las rentas decimales —originariamente poseídas de forma íntegra por las baronías y caballerías - a la Iglesia. La suma de la mitad de las rentas decimales y del patrimonio agrario acumulado, fundamentalmente integrado por algunas caballerías y dominios alodiales, situó a la Iglesia como el segundo señor temporal más importante de la isla, después del monarca.

pensaciones económicas, como en los acuerdos «pariatges» entre el rey y algunos barones y la Iglesia de Mallorca (López Bonet, 1998, pp. 113-127).

${ }_{20}$ Sobre el uso de mano de obra asalariada y esclava en las grandes reservas señoriales y del monarca véase Cateura (1997) y Soto (2000).

${ }^{21}$ Sobre las donaciones de los magnates y señores al obispo y catedral de Mallorca, y los patrimonios de estos últimos véanse los trabajos de Sastre (1990) y López Bonet (1984, 1989).

${ }^{22}$ Parece que el monarca, que fue el primer magnate en ceder una parte de sus diezmos a la Iglesia, también presionó a los barones y señores para que hicieran efectivas estas cesiones del diezmo (Cateura, 1985, p. 75). Los pleitos y presiones que ejerció el obispo sobre los obispos de Barcelona y Gerona, el monasterio de la Real y otros magnates acabaron en 1267 con una primera cesión de un tercio de sus diezmos a la Iglesia. Véase una síntesis en Sastre (1990, pp. 247-248), sobre los pleitos de la Iglesia con el obispo de Gerona véase ADG, Rendes de Mallorca, documentos 231 y 237; y cor el monasterio de la Real, Mora y Adrinal (1982). 
Así pues, la jerarquización de la pirámide feudal reforzó el poder jurisdiccional y económico del rey y de la Iglesia de la isla, mientras se debilitaban la capacidad de sustracción y opresión de los dominios baronales, y de los pequeños dominios nobiliarios. Además, como veremos, la pérdida de poder jurisdiccional y de la mitad del diezmo tuvieron repercusiones desiguales en los distintos dominios señoriales. Por tanto, la política real en la isla fue completamente distinta de la que practicaba en Cataluña o Valencia. Mientras en la isla los barones y pequeños nobles a lo largo de los siglos XIII y XIV no tuvieron ninguna oportunidad de reforzar su poder o aumentar la extensión de sus dominios, en el continente la nobleza consiguió aumentar sus dominios y rentas en detrimento del patrimonio real ${ }^{23}$.

\section{LOS INGRESOS Y LAS ESTRATEGIAS ECONÓMICAS DE LA NOBLEZA FEUDAL}

En este apartado intentaremos mostrar cómo los repartimientos y la jerarquización del poder feudal condicionaron la organización e ingresos de los dominios del monarca, los barones y la pequeña nobleza. Para ello hemos reconstruido la composición de los ingresos de estos grupos nobiliarios, que en cierta medida son un reflejo o indicador de las formas de exacción sobre el campesinado o sobre el excedente económico. La consolidación de un tipo u otro de renta nos hablará de las diferentes estrategias económicas por las que optaron, o las que se vieron obligados a seguir los distintos grupos nobiliarios.

En el cuadro 1 hemos sistematizado los ingresos de los dominios feudales del monarca. En el primer panel tenemos la composición de la renta para los años inmediatamente posteriores a la conquista, donde se puede apreciar que los derechos dominicales representaban el grueso de sus ingresos totales con cerca del 60 por 100 de los ingresos totales -un 24 por 100 de las rentas dominicales de las baronías y otro 36 por 100 de los

${ }^{23}$ El monarca había seguido una política dubitativa en los años posteriores a la conquista (1233-1242/5), pues había concambiado sus dominios en la isla con los que el Infante Pere de Portugal tenía en el principado. Pero desde el decenio de 1240 su estrategia se encaminó a incrementar sus dominios y poder jurisdiccional sobre la isla (Soto, 1990, 1994; Cateura, 1997). En cambio, en Cataluña a lo largo de los siglos XII.XIV alienó numerosos dominios a favor de los condes y barones (Ferrer Mallol, 1970/1; Tello, 1995, pp. 40-41), también en el País Valenciano se produjo una progresiva señorialización del territorio entre la conquista y finales del siglo XIV (Guinot, 1997). 
CUADRO 1

Composición de los ingresos de los dominios feudales del monarca en Mallorca

\begin{tabular}{|c|c|c|c|c|c|}
\hline & 1245 & & 1317 & $1343-46$ & $1358-60$ \\
\hline \multirow[t]{6}{*}{ Rentas de las baronías ${ }^{1} . .}$. & 23,6 & Rentas de las baronías ${ }^{2}$. & 8,8 & 4,6 & 6,0 \\
\hline & & Laudemios... & 10,3 & 9,2 & 12,1 \\
\hline & & Monopolios (hornos, ...) & 3,6 & 1,3 & 0,9 \\
\hline & & Jurisdiccionales.................... & 9,2 & 1,0 & 2,2 \\
\hline & & Censos.. & 12,5 & 1,5 & 2,1 \\
\hline & & Varios y extraordinarios. & 2,9 & 14,3 & 8,1 \\
\hline Derechos dominicales $^{3} \ldots .$. & 36,4 & Diezmos ............................... & 33,2 & 66,7 & 66,6 \\
\hline Monopolios comerciales ... & 24,5 & Monopolios comerciales & 19,5 & 1,3 & 2,0 \\
\hline Reservas $^{4} \ldots \ldots \ldots \ldots \ldots \ldots \ldots$ & 15,4 & Reservas $^{5} \ldots$ & - & - & - \\
\hline Total. & $.100,0$ & Total & $.100,0$ & 100,0 & 100,0 \\
\hline
\end{tabular}

1 Los ingresos de este año correspondían a la recién incorporada baronía del Conde Nunó Sanç.

${ }^{2}$ Hasta mediados del siglo xrV los dominios de los barones incorporados al real patrimonio se gestionaban separadamente, aunque la composición de la renta en cada uno de ellos era muy semejante a la que proporcionaban los dominios reales.

${ }^{3}$ En esta partida se incluyen los diezmos, tascas, censos, monopolios, etc., que se arrendaban conjuntamente por distritos.

${ }^{4}$ A mediados del siglo XIII el monarca tenía 5 reservas destinadas a la producción agraria, que fue vendiendo posteriormente.

${ }^{5}$ En estos años al monarca le quedaban únicamente las reservas de caza que fueron vendidas, finalmente, en el año 1350.

Fuente: Elaboración a partir de los datos de Cateura (1997, pp. 106-108) y López Bonet (1989).

dominios propios-, los monopolios comerciales y la actividad económica que generaba el intenso tráfico portuario de la ciudad representaba cerca del 25 por 100 , y, por último, la explotación directa de las cinco reservas reales, explotadas con mano de obra esclava y asalariada, aportaban cerca del 16 por 100 de los ingresos totales. Como veremos, los ingresos del monarca constituían un caso atípico, sobre todo por el monopolio que tenía sobre los ingresos de carácter fiscal que gravaban el consumo, el tráfico o las actividades comerciales o portuarias, estos ingresos le permitirian un mayor margen de maniobra frente a los otros barones.

La información que hemos conseguido reunir sobre los ingresos de los dominios del resto de barones es relativamente escasa, generalmente sólo disponemos de referencias de carácter indirecto. En algunos de los 


\section{CUADRO 2}

Ingresos del obispo de Mallorca y de algunos patrimonios de la pequeña nobleza (en porcentajes)

\begin{tabular}{|c|c|c|c|c|c|}
\hline \multicolumn{2}{|c|}{ Rentas del Obispo de Mallorca } & \multicolumn{4}{|c|}{ Rentas de la pequeña nobleza feudal } \\
\hline \multicolumn{2}{|l|}{ Obispo de Mallorca } & \multicolumn{2}{|r|}{ Rubert } & \multirow{2}{*}{$\frac{\text { Puigdorfila }}{1355}$} & \multirow{2}{*}{$\frac{\text { Nunis }}{1370-5}$} \\
\hline Partidas & $1359-63$ & Partidas & 1369 & & \\
\hline Diezmos & . 55,1 & Diezmos ............ & $62,3^{1}$ & 9,8 & 19,3 \\
\hline Censos ............................. & 9,3 & Censos y laudemios ... & - - & 27,7 & 50,0 \\
\hline Laudemios...................... & 4,9 & & & & \\
\hline Otros ............ & 15,5 & Otros .......................... & - & - & 2,3 \\
\hline \multirow[t]{2}{*}{ Reserva señorial.. } & 15,3 & Reserva señorial.. & 2,1 & 62,5 & 28,4 \\
\hline & & Alquerías y tierras ...... & 35,6 & 一 & - \\
\hline Total. & 100,0 & Total. & 100,0 & 100,0 & 100,0 \\
\hline
\end{tabular}

${ }^{1}$ Esta cifra contiene el valor de los diezmos, tascas, censos y laudemios de este feudo. FuENTE: Los ingresos del obispo de Mallorca se han obtenido del inventario publicado por Hillgarth (1958/9, pp. 503-554); los de la casa Nuniç proceden de ACM, PN, 14678 (1370) i 14679 (1375), los de la casa Rubert de ARM, SU.25, ff. 339 ss.; y los de la casa Puigdorfila de ARM, SU-199, ff. 35-157v.

inventarios de los dominios baronales incorporados por la corona a finales del siglo XW o comienzos del siglo XIV, además de las rentas derivadas de los derechos feudales, aparecen mencionadas algunas alquerías no establecidas, que constituían las reservas señoriales, cultivadas también con mano de obra esclava y asalariada ${ }^{24}$. La información más sólida que disponemos es la que se ha conservado sobre el patrimonio del obispo de Mallorca. En el inventario del 1359/63, resumido en el cuadro 2, nos muestra claramente el predominio del diezmo en sus ingresos, fruto de los pactos anteriormente mencionados, y la menor importancia que tenían otros derechos dominicales o feudales. También, en este caso, el inventario describe con todo detalle la explotación directa de dos alquerías: la de Aranjassa, situada en el llano de Palma, y la de Tofla en la sierra de Tramontana, la venta de los excedentes agrarios de estas explotaciones representaban

${ }^{24}$ Véanse los inventarios de los dominios de los barones incorporados por el real patrimonio y sobre las reservas de los dominios de las órdenes militares en Cateura (1982b). 
un 15 por 100 de los ingresos totales del patrimonio ${ }^{25}$. Sin embargo, los cabreves o inventarios de los dominios de otros magnates sugieren que no todos habían poseído tierras en dominio pleno, o bien que éstas habían sido establecidas antes de mediados o finales del siglo xiII. Los ingresos de estos dominios, probablemente desde los años inmediatamente posteriores a la conquista, procedían fundamentalmente de los censos, tascas y diezmos, y otros de carácter dominical o jurisdiccional ${ }^{26}$.

La documentación sugiere, pues, que hasta finales del siglo xuI es probable que algunos magnates conservaran una parte de sus tierras en dominio pleno, y aprovecharan las posibilidades que ofrecía la explotación directa de las reservas señoriales, especialmente de aquellas que estaban en las inmediaciones de la ciudad, donde se concentraba el mayor mercado de la isla. Pero, entre finales del siglo XIII y mediados del XIV, la mayoría de las reservas de los dominios de los barones, el monarca y el obispo fueron establecidas o vendidas ${ }^{27}$. Por tanto, podemos afirmar que en general las reservas de los magnates tuvieron una vida efímera, o quedaron reducidas a la mínima expresión, de manera que sus ingresos dependían fundamentalmente de la renta feudal - diezmos, tascas, censos, monopolios, etc.- Como puede apreciarse en la evolución de la composición de los ingresos de los dominios feudales del monarca, el diezmo y la tasca, las rentas proporcionales a la cosecha, en el decenio de 1340 ya aportaban el grueso de sus ingresos, cerca del 67 por 100. Mientras que otras partidas fueron menguando por razones diversas. En algunos casos debido a que

${ }^{25}$ Estas alquerías eran gestionadas directamente con mano de obra esclava y asalariada, y su producción se destinaba sobre todo al consumo del obispado y sus dependientes, y en menor medida se comercializaba.

${ }^{26}$ Por ejemplo, en la documentación publicada de los dominios del conde de Ampurias, del Paborde de Tarragona, el obispo de Barcelona, no aparecen referencias a reservas señoriales, ni tampoco en la baronía del obispo de Gerona, no aparece ninguna mención a reservas señoriales. Véanse los cabreves de la baronía del obispo de Gerona de 1289 y 1333 en $A D G$, pergaminos números $255,356,258,278,284,283,285$.

27 En gran medida ello debió ocurrir después de la incorporación de estos dominios al patrimonio real, pues en los inventarios realizados cuando estos dominios de los barones fueron incorporados por el monarca aún aparecen las alquerías que habían constituido hasta ese momento las reservas señoriales (Cateura, 1982b, 1997). La explotación de Beniatzar se mantuvo en dominio pleno hasta finales del siglo xII; véase, por ejemplo, el arrendamiento de 1282 (Soto, 1991, apéndice documental, doc. 421). Posteriormente fue vendida a la casa Puigdorfila, perteneciente a la pequeña nobleza feudal. Los cotos de caza, las alquerías o dehesas que poseía en la parroquia de Artà fueron vendidas en 1350, y también otros inmuebles fueron alienados (Ramis d'Ayreflor, 1952). También el obispo de Mallorca vendió una de sus alquerías, Tofla, con lo que su patrimonio territorial quedó muy menguado. Sobre las reservas de las baronías de los magnates y el monarca ver Cateura (1982b, pp. 79-130, 1986, 1988, 1997), Soto (1991, 2000, pp. 21-24). 
estas rentas, como en el caso de los censos sobre algunas parroquias, fueron donados a la Iglesia, en otros casos, como es el de los monopolios feudales sobre el tráfico, el consumo o el comercio, fueron progresivamente sustituidos por otras imposiciones, de carácter fiscal, que eran más eficaces desde la perspectiva impositiva y de la gestión recaudatoria ${ }^{28}$. Parece que también el obispo de Mallorca optó por esta estrategia, y algunos datos posteriores sugieren que estos ingresos se convirtieron en el eje de la sustracción de los magnates ${ }^{29}$.

De esta forma podemos argumentar que, si en un primer momento los grandes magnates intentaron gestionar directamente algunas de sus explotaciones, esta estrategia fue progresivamente abandonada a lo largo de la segunda mitad del siglo xwl, y que su peso en el conjunto de las rentas era muy poco importante. La estrategia dominante en los patrimonios mallorquines de los barones era parecida a la que llevaban a cabo en el Principado, y que podemos calificar como poblacionista. Es decir, su estrategia pasaba por ofrecer tierras en establecimiento en buenas condiciones para atraer pobladores, y así aumentar el volumen de sus ingresos. Por consiguiente, ello implicaba que habían librado la capacidad de ordenar el espacio y organizar la producción agraria a otros grupos sociales, fundamentalmente a aquellos que poseían el dominio útil o pleno sobre la tierra ${ }^{30}$.

La estrategia dominante en los grandes magnates contrasta con la que reflejan los ingresos de los patrimonios de la pequeña nobleza, poseedora de caballerías y de dominios directos. Ya en la parca documentación del siglo XIII podemos encontrar referencias a la importancia que tenía la explotación de la reserva señorial en los patrimonios de la pequeña nobleza. En el inventario de los bienes y rentas del Maestro Joan, Paborde de la Catedral de Ciutat de Mallorca, de 1276, la explotación de las tierras con mano de obra esclava aparece como un elemento central de su riqueza ${ }^{31}$. Algo semejante sugieren los inventarios de la casa Torrella realizados en 1312. Esta casa poseía feudos en las parroquias de Sóller y Muro, y en ambos dominios mantenía una alquería en dominio pleno explotada con mano de obra esclava

${ }^{28}$ Sobre el desarrollo de la fiscalidad pública y real a partir de finales del siglo xm véase López Bonet (1986, 1991, p. 62), Cateura (1998, 1999).

${ }^{29}$ Sobre los ingresos del obispo y otros barones para la etapa posterior al siglo XIV véase Jover y Soto (1997, p. 265) y Jover (1997, pp. 278-282).

${ }^{30}$ Esta estrategia poblacionista fue definida por Bloch (1978, pp. 249-251), y posteriormente formalizada por Barceló (1981, p. 236).

${ }^{31}$ Soto (1991, doc. 378). 
y asalariada ${ }^{32}$. Otro ejemplo es el del monasterio de la Real. Esta institución poseía varios feudos en tres parroquias (Deià, Manacor, Esporles) y Palma, además tenía en explotación directa hasta finales del siglo xuI la alquería de la Real en Manacor, posteriormente establecida, y también hasta finales del siglo XIV gestionó directamente las alquerías de la Granja (Esporles) y las ricas tierras irrigadas que rodeaban el convento en la ciudad. Estas alquerías en dominio pleno eran explotadas directamente con mano de obra esclava y asalariada ${ }^{33}$. También, los inventarios de las casas Tornamira, poseedora del feudo de la Galera en la parroquia de Felanitx (1343-1350), y de la casa Saverdera, poseedora de un feudo en Muro (1346), describen una estructura bipartita del feudo, donde se mantenía una alquería explotada directamente, mientras el resto de las tierras habían sido establecidas. La casa Puigdorfila, según las cuentas e inventarios de sus feudos de Banyols y Masnou (1320-1348), mantenía dos alquerías en dominio pleno, una de ellas, Masnou, explotada directamente con mano de obra asalariada y esclava, y la otra especializada en la producción oleolícola ${ }^{34}$.

La estructura bipartita de los feudos de la pequeña nobleza queda claramente reflejada en la composición de los ingresos de algunos dominios. Aunque solamente hemos encontrado valoraciones o contabilidades para el período inmediatamente posterior a 1350, la documentación sugiere que no habia habido cambios sustanciales en las modalidades de organización y gestión de los dominios señoriales ${ }^{35}$. Como puede verse en el cuadro 2 , la proporción que representaban los ingresos que proporcionaba la reserva señorial respecto de los ingresos totales, en los tres ejemplos es notablemente superior al que hemos visto en los magnates: entre un tercio y dos tercios de los ingresos totales. Incluso, en uno de estos patrimonios, la casa Rubert, donde la reserva señorial era relativamente pequeña, la familia había conseguido adquirir una alquería, en dominio útil, en las inmediaciones de la ciudad, que explotaban directamente ${ }^{36}$.

${ }^{32}$ Esta casa había recibido estos feudos como feudatario del obispo de Girona y del Conde de Ampurias, asimismo estaba emparentada con el primer obispo de la Isla, Guillem de Torrella. Véase Pérez (1994, pp. 69-96) y el inventario de 1312 en ARM, AGT, 11, 32 , inventarios en pergamino, número 2.

${ }^{33}$ Mora y Adrinal (1982).

${ }^{34}$ Sobre la gestión de estos dominios véase Jover y Soto (1997, pp. 238-246) y Jover, Mas y Soto (2002).

${ }^{35} \mathrm{Si}$ exceptuamos la sustitución de trabajo asalariado fijo y jornalero por mano de obra esclava, véase al respecto Jover, Mas y Soto (2002).

${ }^{36}$ También podemos encontrar ejemplos semejantes en otros dominios como el de la casa Sant Joan, que poseian el feudo llamado de los Monjos, en el cual no tenía reserva 
El peso de los ingresos de la reserva señorial en la reproducción económica de estos patrimonios se revela, pues, más importante que en los grandes dominios de los barones, y sugiere que la estrategia que siguió la pequeña nobleza tenía un remarcable sesgo rentabilista, es decir, buscaban en la explotación de la reserva los ingresos que, al parecer, no podían conseguir mediante la parcelación y poblamiento de sus dominios. La elección de esta vía de organización del feudo en la pequeña nobleza plantea algunos interrogantes relevantes para entender la consolidación de la estructura feudal y del proceso de colonización, así como para comprender el peculiar desarrollo agrario de la isla en la centuria posterior a la peste negra: ¿Por qué mantuvieron estos señores la estructura bipartita del feudo?, ¿́por qué no optaron por establecimiento de la totalidad de las tierras que poseían? A estas preguntas intentaremos responder en los próximos apartados.

\section{COLONIZACIÓN FEUDAL, PAISAJES AGRARIOS Y POBLAMIENTO}

Nuestro propósito en este apartado es mostrar cómo los procesos de colonización agraria, a lo largo de los más de cien años posteriores a los diferentes repartimientos, estuvieron mediatizados por diversos factores de carácter socio-ambiental. En particular nos referiremos a las restricciones que impusieron los paisajes agrarios heredados por los colonos y señores feudales, al desarrollo agropecuario, y particularmente cómo aquéllos condicionaron la organización del territorio y el asentamiento de la población (hábitat, densidades, niveles de urbanización) ${ }^{37}$. Nuestro argumento puede resumirse de esta forma: en cierta medida los pobladores y señores feudales fueron, en las primeras etapas de la colonización, prisioneros de los espacios agrosilvopastorales legados por las comunidades andalusíes ${ }^{38}$. Para captar estos procesos utilizaremos algunos indicadores de carácter demográfico: las densidades de población y el número de núcleos de población con-

señorial, pero había adquirido dos alquerías en la parroquia de Bunyola y Campanet, cercanas a la ciudad y productoras de aceite, cereales y vino. Véase ARM, SU-27, f. 56-130.

${ }^{37}$ Los paisajes agrarios que encontraron los colonizadores, por otra parte, no eran eco-

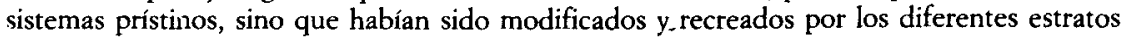
sociales que se habían superpuesto (Tello, 1999, pp. 195-214). La colonización feudal en Mallorca se impuso sobre los espacios agrarios organizados por las poblaciones andalusíes, véase al respecto Guichard (1976), Barceló y Kirchner (1995), Kirchner (1997) y Soto (1991).

${ }^{38}$ Este argumento lo desarrollamos en Jover y Soto (en prensa). 


\section{CUADRO 3}

Hogares y densidades, según el «fogatge del morabati», 1329-1364

\begin{tabular}{|c|c|c|c|c|c|}
\hline \multirow{2}{*}{ Comarcas } & \multirow{2}{*}{$\begin{array}{l}\text { Número } \\
\text { de núcleos } \\
\text { de bábitat } \\
\text { concentrado }\end{array}$} & \multirow{2}{*}{$\begin{array}{c}\text { Extensión } \\
\left(\mathrm{km}^{2}\right)\end{array}$} & \multicolumn{3}{|c|}{ Número de bogares } \\
\hline & & & 1329 & 1343 & 1364 \\
\hline 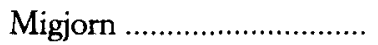 & 5 & 1.119 & 1.048 & 1.160 & 1.188 \\
\hline 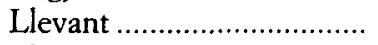 & 1 & 229 & 224 & 243 & 242 \\
\hline $\mathrm{Pla}$ & 13 & 786 & 1.750 & 1.786 & 1.623 \\
\hline 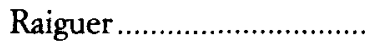 & 7 & 285 & 1.847 & 1.900 & 1.438 \\
\hline 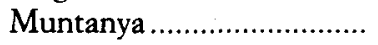 & 18 & 952 & 2.146 & 2.048 & 1.450 \\
\hline \multirow[t]{2}{*}{ 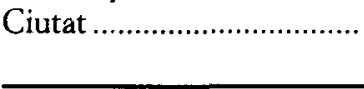 } & 1 & 209 & 5.398 & 4.126 & 4.910 \\
\hline & & 3.580 & 12.243 & 11.263 & 10.851 \\
\hline \multirow{2}{*}{ Comarcas } & \multirow{2}{*}{$\begin{array}{c}\text { Núcleos } \\
\text { de población } \\
\left(\mathrm{km}^{2}\right)\end{array}$} & \multirow{2}{*}{$\begin{array}{c}\text { Distribución de } \\
\text { la población } \\
\text { en } 1329 \\
(\%)\end{array}$} & \multicolumn{3}{|c|}{ Hogares $/ \mathrm{Km}^{2}$} \\
\hline & & & 1329 & 1343 & 1364 \\
\hline 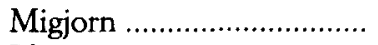 & 223,8 & 8,4 & 0,9 & 1,0 & 1,1 \\
\hline 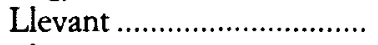 & 228,8 & 1,8 & 1,0 & 1,1 & 1,1 \\
\hline Pla & 60,5 & 14,1 & 2,2 & 2,3 & 2,1 \\
\hline 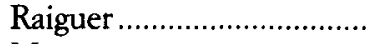 & 40,7 & 14,9 & 6,5 & 6,7 & 5,0 \\
\hline 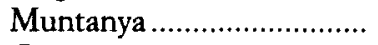 & 52,9 & 17,3 & 2,3 & 2,2 & 1,5 \\
\hline 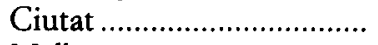 & 209,0 & 43,5 & 25,9 & 19,8 & 25,5 \\
\hline 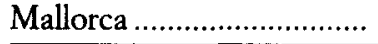 & - & 100,0 & 3,5 & 3,1 & 3,0 \\
\hline
\end{tabular}

FuENTE: Sevillano Colom (1974). Sobre el número de núcleos de población concentrada que había en las diferentes parroquias, véanse Ramis d'Ayreflor (1935) y Miralles Montserrat (1988, pp. 445-462).

centrada existentes en las parroquias de la isla que reflejan los «fogatges» - hogares-del segundo cuarto del siglo XIV ${ }^{39}$. Estos índices, que hemos recogido en el cuadro 3 , nos proporcionan una primera guía para interpretar la estructura de ocupación del espacio agrario. En primer lugar nos referiremos a las modalidades y pautas de urbanización y hábitat que reflejan estas fuentes, para seguidamente detenernos en el análisis de las densidades.

El primer rasgo a tener en cuenta es que la nueva estructura del hábitat feudal rompería con las modalidades de asentamiento rural clánico de los

${ }^{39} \mathrm{El}$ «fogage del morabatí» era un impuesto septenal establecido en 1300 para mantener la moneda de la isla (Sevillano Colom, 1974). 
andalusíes, en el que las alquerías constituían pequeñas agrupaciones rurales donde habitaban familias extensas. En la posconquista la mayoría de estas alquerías y rafales se transformaron en explotaciones unifamiliares autónomas de gran tamaño; y, por otra parte, la parcelación y el establecimiento de algunas de esas alquerías dio como resultado la formación de nuevas villas ${ }^{40}$. La emergencia de esta nueva dicotomía entre villa, como modalidad de hábitat concentrado de diversas familias, y alquería o rafal, como explotaciones compactas unifamiliares de gran extensión, marcó la primera gran ruptura en las modalidades de asentamiento. La segunda fue la rápida multiplicación de las villas, o de los núcleos de hábitat concentrado ${ }^{41}$.

La segunda característica que debemos destacar es la importancia demográfica que tenía la ciudad en el conjunto de la isla, ya desde el siglo XIII. Los indicadores del cuadro 3 permiten apreciar que durante la primera mitad del siglo xIv la densidad demográfica media de Mallorca era similar a la de Cataluña. Sin embargo, la distribución de la población rural y urbana, y las pautas de ocupación del suelo eran muy diferentes ${ }^{42}$. El distrito de la Ciutat de Mallorca, sin duda el más importante y también, paradójicamente, el menos conocido, concentraba alrededor del 40 por 100 de la población y alcanzaba unas densidades de en torno a 26 hogares $\mathrm{km}^{2}$ (en torno a 100 habitantes por $\mathrm{km}^{2}$ ). Esta macrocefalia de la ciudad respecto del resto del territorio probablemente se pueda explicar a partir

${ }^{40}$ Sobre el poblamiento rural andalusí ver un breve estado de la cuestión en Kirchner (1997, pp. 47-54).

${ }^{41}$ Ya desde el siglo xrv los términos de las villas se superponían con las unidades de administración eclesiástica, las parroquias. Así, las universidades (concejos) rurales y las parroquias se convirtieron en unidades administrativas y de exacción fiscal para el monarca y la Iglesia. En general, la villa era el centro de residencia y administración más importante del distrito parroquial, donde se encontraba la universidad, la iglesia parroquial, el mercado, los bailes reales y señoriales, etc. Sobre la formación de las universidades y las partoquias véase Planas (1995), López Bonet (1995) y Mas (2000).

${ }^{42}$ En Cataluña las densidades anteriores al 1350 eran de alrededor de 16 habitantes por $\mathrm{km}^{2}$ mientras en la isla eran de unos $13 \mathrm{hab} / \mathrm{km}^{2}$; hacia $1360 / 70$ las densidades eran aproximadamente de $13 \mathrm{hab} / \mathrm{km}^{2}$ en Cataluña, 12 en Mallorca, y 5 en el País Valenciano. Por último, a finales del siglo xv eran de $8 \mathrm{hab} / \mathrm{km}^{2}$ en Cataluña, 7,5 en Mallorca y 11 en el País Valenciano. Por otra parte, mientras Barcelona no representaba más del 6-10 por 100 de la población total del principado durante los siglos xIV y XV, en el País Valenciano los datos posteriores al 1350 muestran que Valencia concentraba en torno a un 20-25 por 100 de la población total, y como se puede ver en la tabla, la población de Ciutat respecto del total de la isla caería de un 44 por 100 a algo más de un 20 por 100 . Estos datos sugieren unas evoluciones de la población, de la ocupáción del territorio y de la jerarquía urbana muy diferentes, que habría que analizar comparativamente. Ver un resumen de la evolución de la población de Cataluña, el País Valenciano y Mallorca en HSPCPC, vol. III (1996, pp. 76-95). 
de la importancia que tenía la urbe como centro político-administrativo, residencial, comercial y portuario, y también por la agricultura intensiva que se practicaba en la corona de tierras irrigadas que la circundaban ${ }^{43}$. La distribución de la población en la llamada «Part Forana», es decir, los distritos rurales, muestra, por el contrario, unas densidades relativamente bajas, y con fuertes contrastes comarcales. Así pues, mientras parece que la ciudad se convirtió en un polo de atracción importante para los recién llegados, las desiguales y bajas densidades de las diferentes comarcas rurales podrían ser un indicio de las dificultades con que se encontrarían barones y caballeros para asentar a los colonos en sus dominios feudales.

La extensión de los términos de las villas, que se superponían con los distritos parroquiales, y el número de núcleos de hábitat concentrado que había en ellos, revela una primera diferencia importante en la estructura urbana de la isla. Así, los términos de las villas que se crearon en la comarca del Raiguer, y en los valles de la sierra de Tramontana, eran relativamente pequeños, y en ellos podemos encontrar más de dos núcleos de población. En cambio, en las comarcas del $\mathrm{Pla}$, Llevant y Migjorn —-situadas en el centro y este de la isla - se formaron parroquias muy extensas, y el poblamiento se concentraba en una gran villa ${ }^{44}$. Fuera de estos perímetros urbanos, y de la corona de tierras cultivadas que los envolvía, se extendían las grandes explotaciones de los terratenientes de la ciudad, de los campesinos acomodados de la parroquia o las reservas señoriales de las caballerías. En las parroquias del Raiguer este anillo de grandes explotaciones era relativamente estrecho, excepto en las pendientes de la Sierra, porque, como hemos dicho, el parcelario estaba muy fragmentado y los núcleos habitados se situaban a pocos kilómetros unos de otros (cuadro 3, columna: $\mathrm{km}^{2} /$ núcleos de población). En cambio, en las parroquias del centro y este de la isla, el radio de este anillo de grandes explotaciones era mucho más amplio, y las alquerías y rafales tenían una extensión media muy superior

${ }^{43}$ Frente a las numerosas historias locales que proporcionan información documental de prácticamente todos los municipios de Mallorca, apenas hay nada sobre el distrito de la ciudad, pese a que la información documental proporcionada por los registros mallorquines es muy abundante. Sobre la importancia comercial y manufacturera de la ciudad, Riera Melis (1986), Bernat (2000, pp. 41-54) y Abulafia (1996). Para la importancia de la agricultura y especialmente del regadío en el término de la ciudad, véanse las notas que aporta Riera Frau (1993) para la etapa andalusina, y para la etapa posterior, Barceló Crespí (1988a), Rosselló Verger (1959) y Rosselló Vaquer (1989, pp. 91-103).

${ }^{44}$ Como veremos posteriormente, los intentos de densificar la trama urbana en estas comarcas fracasaron. 
a las del Raiguer ${ }^{45}$. De este modo, podemos observar un relativamente precoz hábitat concentrado en grandes villas en el este y sur de la isla, mientras que la urbanización del Raiguer era más difusa, ya que allí, en torno a una villa relativamente grande podemos encontrar una pequeña constelación de pequeñas aldeas o agrupaciones de casas. Así pues, unos índices de urbanización relativamente elevados podían reflejar estructuras de población muy distintas.

El análisis de las densidades de población nos permite distinguir, ya durante la primera mitad del siglo XIV, cinco grandes zonas de poblamiento rural, que podemos identificar con las cinco comarcas en que históricamente se ha dividido la isla ${ }^{46}$. Como muestra el cuadro 3, las densidades más elevadas las encontramos en las parroquias que integran la comarca denominada el Raiguer, cerca de 6 hogares por $\mathrm{km}^{2}$, que aparece como una prolongación de la corona de la ciudad en dirección noreste, siguiendo la solana de la Sierra de Tramontana. En segundo lugar, aunque las densidades medias de las parroquias de la Sierra de Tramontana sean relativamente bajas $\left(2,5\right.$ hogares por $\left.\mathrm{km}^{2}\right)$, debemos distinguir entre las elevadas densidades de población que se daban en los valles que se abrían hacia el llano, de las parroquias que ocupaban las zonas más elevadas y abruptas de la Sierra de Tramontana, donde los niveles de poblamiento se mantuvieron muy bajos ${ }^{47}$. Este relativo éxito colonizador de los valles y la solana de la Sierra de Tramontana fue debido en parte a las ventajas naturales de aquellas comarcas. En estas parroquias se dan unas precipitaciones relativamente abundantes en el contexto de la isla, lo que da lugar a la disponibilidad de reservas hídricas considerables, mientras que

${ }^{45}$ Estos datos los inferimos de la denominación de las tenencias y de las extensiones medias de las explotaciones que aparecen en los catastros del siglo XIX. En general, las grandes explotaciones no se fragmentaron mucho, según los ejemplos estudiados. Ver los trabajos de Ramis d'Ayreflor (1933, 1952), Gili (2000), Obrador (1992), Soto (1991, 1994) y Mas (2000).

${ }^{46}$ La división contemporánea de la isla en cinco demarcaciones o comarcas, la Sierra de Tramuntana (Muntanya), el Pla, el Raiguer, el Migjorn y el Llevant, hecha por geógrafos durante los años sesenta y setenta, atendía básicamente a criterios climáticos, orográficos y edáficos (Bisson, 1977, p. 120). Ahora bien, una división muy similar ya se puede encontrar en los registros fiscales y en las descripciones de los coetáneos en los siglos XII y XIV, y que se mantendría a lo largo de la Edad Media y Moderna (Capó Villalonga, 1985, p. 195; Cateura, 1998, 1999, p. 106).

${ }^{47}$ Por ejemplo, en las parroquias con las altitudes y las pendientes medias más elevadas, donde las dificultades orográficas imponian límites a la colonización, como las parroquias de Bunyola, Puigpunyent, Estellencs, Deià, Banyalbufar y Escorca. En estos lugares, las pendientes medias iban desde el 30 por 100, hasta más del 40 por 100 , mientras la altitud media de estas parroquias era superior a 400 metros, véase Carbonero (1992, pp. 203-206). 
los suelos son relativamente ricos en nutrientes y materia orgánica ${ }^{48}$. Pero también fue debido a que la capacidad productiva de estas zonas había sido implementada por las comunidades andalusíes en los siglos X-XIII, que dejaron una amplia infraestructura-campos cultivados, casas, molinos, norias, caminos, núcleos de población ya estructurado, redes de regadío y conducción de aguas - que permitiría poner en cultivo y explotar inmediatamente aquellas tierras. Además, estos distritos estaban situados muy cerca de los núcleos urbanos más importantes de la isla (Pollença, Alcúdia, Inca) y del gran centro comercial y portuario que era la Ciutat ${ }^{49}$. La combinación de estos factores socio-ambientales explicaría el rápido poblamiento de estas zonas, las elevadas densidades y la urbanización difusa que caracteriza estas parroquias, muy semejante a la que podemos encontrar en las tierras de origen de la mayoría de los colonos ${ }^{50}$.

A medida que nos desplazamos hacia el centro de la isla, la comarca del Pla, o hacia el noreste, el Llevant, o el sureste, la comarca del Migjorn, podemos observar una progresiva disminución de las densidades demográficas y de la densidad de la red urbana. Como puede verse en el cuadro 3 , en general en las parroquias del centro la densidad media es de 2,2 fuegos por $\mathrm{km}^{2}$ y en el este de la isla no alcanzaban un hogar por $\mathrm{km}^{2}$. Además, en estas zonas la población tendió a concentrarse mucho más en grandes villas, en cada parroquia había generalmente un único núcleo de población concentrada. Las bajas densidades y la fuerte concentración de la población sugieren que las dificultades en la colonización y explotación de estas tierras fueron mucho mayores que en el Raiguer y los valles de la Sierra de Tramontana. Y, probablemente, el peso de los factores ambientales tenga un

${ }^{48}$ Véase una descripción de las condiciones naturales de estas tierras en Bisson (1977, pp. 17-19). Sobre la distribución de las precipitaciones y zonas de captación de aguas en la isla ver los estudios de Carbonero (1992, pp. 32-44); y sobre los suelos y el clima ver el volumen primero de la obra de Guillermo Colom (1978). Según la crónica de Marsili, en la época de la conquista «Les muntanyes són pedregoses no cunvinents a negunes semén, seches, nues sens fruit, sens utilitat, més en lo peu de les muntanyes, bi ba viles delectables, oliveres fructuoses, abundancia de vinyes $i$ de diverses fruites, vergers molt agradables $i$ fonts cascuna part corrents ... beven de pous $i$ aigües recollides en cisternes» Citado en Piferrer y Quadrado (1888, p. 577).

${ }^{49}$ Estas villas ya constituían núcleos de población concentrados en la etapa andalusí, quizás mercados locales (Soto, 1979).

${ }^{50}$ La mayoría de los colonos procedían de la región de Girona, y concretamente de la zona litoral o prelitoral (Selva, Empordà, Gírona), donde el hábitat era muy disperso, y la estructura del parcelario estaba a principios del siglo xIV muy fragmentado. Sobre el paisaje agrario de esta zona véase Mallorquí $(1998,2000)$, y sobre la composición de los colonos que ocuparon las tierras del Raiguer y los valles de la Sierra de Tramontana véase Mas (1994). 
papel relevante en la comprensión de la ocupación del suelo en estas comarcas. De entrada, los índices de aridez que se registran en las tierras del sureste son muy elevados, mientras que los suelos son generalmente muy pobres en materia orgánica - excepto en algunos lugares privilegiados-, y las fuentes o corrientes superficiales de agua que había en aquellas parroquias - excepto en Artà- eran escasas ${ }^{51}$. Estos factores condicionarían el proceso de colonización de las tierras orientales de la isla. Las alquerías situadas en esta zona, ya en la época andalusí, según los repartimientos reales (1232) y de Nunó Sanç (1240), tenían una extensión media superior a la que tenían las del Raiguer; y en gran medida se dedicaban a aprovechamientos silvopastorales, síntomas ambos de la escasa ocupación del espacio agrario ya antes de la conquista feudal ${ }^{52}$. No debe extrañarnos, pues, que los barones también encontraran dificultades para poblar estas tierras, y que muchas de las alquerías fueran abandonadas durante la segunda mitad del siglo XIII ${ }^{53}$. De hecho, la agricultura colonial - con las densidades y técnicas de los siglos XIII y XIV- se consolidó a partir de los anteriores asentamientos andalusíes, ceñidos a los perímetros irrigables que permitían los pozos de agua y a las tierras más fértiles. Alrededor del núcleo urbano se desarrolló un primer anillo, relativamente reducido, de agricultura intensiva, y en un segundo anillo se extendían las grandes tenencias dedicadas a las actividades pecuarias o silvícolas ${ }^{54}$.

\$1 A pesar de que las precipitaciones en algunas zonas pudieran ser relativamente elevadas $(500-700 \mathrm{~mm}$ ), su carácter torrencial, la elevada evapotranspiración, y una estructura orográfica y pedológica que dificultaba la retención y el aprovechamiento de las aguas, reducían enormemente los caudales de agua, superficiales o del subsuelo, técnicamente aprovechables en la época. Por otro lado, una gran parte de los suelos de aquellos distritos son calcáreos y tienen un bajo contenido en materia orgánica, y la vegetación está dominada por las garrigas; sólo en los suelos más ricos se podian encontrar formaciones arbóreas más densas con pinos y encinas. Se puede encontrar una cuidadosa descripción geográfica y ambiental de las parroquias del Migjorn de la isla en Rosselló Verger (1964, pp. 58-110), Una aproximación gráfica a la distribución de las precipitaciones, a las cuencas de captación de agua y a los aprovechamientos de ésta se puede encontrar en los mapas elaborados por Carbonero (1992, pp. 35, 37 y 42).

52 Poveda (1985/6) y Barceló y Kirchner (1995).

53 Soto (1992, 1994a), Cateura (1997, p. 45).

54 Los ejemplos de poblamiento estudiados para los distritos de Manacor, Artà y Felanitx nos muestran un poblamiento concentrado en torno a los pozos y fuentes de agua. Mientras en las grandes alquerías dominaba la ganadería extensiva y el cultivo de secano. Las tentativas de extender estos núcleos agrarios, mediante la creación de nuevas poblaciones, y crear un hábitat más denso fracasaron. Véase Barceló y Kirchner (1995, pp. 553-54), Poveda (1992, pp. 5-11), Soto (1992, pp. 13-29; 1994b) y Argemí (1997). 


\section{JURISDICCIÓN FEUDAL, CONFLICTOS INTERSEÑORIALES Y RESISTENCIA CAMPESINA}

Sin embargo, los obstáculos con que toparon los señores feudales y los grandes enfiteutas que poseían las grandes tenencias en dominio útil no eran únicamente de carácter ambiental, como intentaremos poner de relieve en este apartado. Los factores socioeconómicos también tuvieron, a nuestro parecer, un papel decisivo en la formación y consolidación de las pautas de ocupación del suelo que hemos descrito en el apartado anterior. La competencia entre los señores feudales por el control del territorio, las rentas y la jurisdicción, y los conflictos entre los señores y las comunidades campesinas por la distribución de la renta y el control del dominio útil de la tierra modelaron, como intentaremos mostrar, aquellos paisajes agrarios.

En el cuadro 4 hemos sintetizado un índice que nos permite captar los niveles de señorialización en las diversas comarcas de la isla. Este indicador lo hemos calculado a partir del número de caballerías y baronías que poseían señores distintos al monarca, que había en cada parroquia (Nf, Nf/p), y de la extensión que la suma de estos dominios (Ex-f), representaba respecto a la superficie total del término parroquial y comarcal (IS). Por tanto, podemos identificar los niveles de señorialización más intensos donde había más señoríos (caballerías), y donde la superposición de diferentes estratos señoriales era más densa (dominios reales, magnates, barones, señores de caballerías).

En las comarcas del Raiguer y la Sierra de Tramontana los barones (Nunó Sanç, Paborde de Tarragona, Orden de los Hospitalarios, Gastón de Bearn) y el monarca compartían el dominio feudal sobre la mayoría de las parroquias. Sin embargo, el número de señorías o caballerías que estos magnates habían infeudado eran poco numerosas y de una extensión relativamente reducida. Estas circunstancias explican que los niveles de señorialización en estas comarcas sean los más bajos de la isla: las grandes baronías o el dominio real eran el único estrato feudal sobre las tenencias campesinas. Generalmente barones, y sobre todo el monarca, desarrollaron a lo largo del siglo XIII una estrategia caracterizada por la redención de censos, la conmutación de las tascas por censos fijos y la reducción de la tasa de mutación, el laudemio ${ }^{55}$. La combinación de esta disminución

55 Podemos encontrar reducciones de censos y tascas en los dominios de los magnates entre 1270 y 1340, en general, Portella (1985/6, p. 342), Mora y Adrinal (1982, p. 144), 


\section{CUADRO 4}

Niveles de señorialización de la Part Forana

\begin{tabular}{|c|c|c|c|c|c|}
\hline & $N f$ & $N f / p$ & $E x-f$ & IS & $\begin{array}{c}\text { Densidades } \\
1329\end{array}$ \\
\hline & \multicolumn{5}{|c|}{ (Hees) } \\
\hline 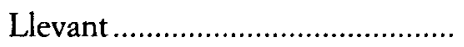 & 15 & 7,5 & - & 0,5 & 1,0 \\
\hline 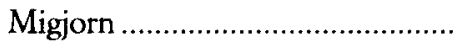 & 38 & 7,6 & - & 0,3 & 0,9 \\
\hline 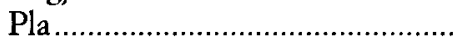 & 45 & 4,5 & 840 & 0,5 & 2,2 \\
\hline 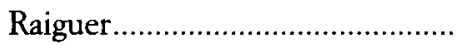 & 11 & 2,8 & - & 0,2 & 6,5 \\
\hline 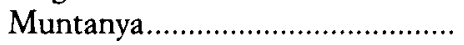 & 37 & 2,8 & 480 & 0,2 & 2,3 \\
\hline
\end{tabular}

Estos indicadores se han calculado a partir del número y extensión de las caballerías y baronías que había en cada una de la parroquias de la isla, sin contar los dominios reales. $\mathrm{Nf}$ : número de caballerías y baronías; $\mathrm{Nf} / \mathrm{p}$ : número de feudos por parroquia; Ex-f; extensión media de la caballería en cada una de las comarcas, realizada a partir de los datos que proporcionan Moll y Suau (1986); IS: índice de señorialización calculado a partir de la multiplicación de la extensión media del feudo por el número de feudos que había en cada parroquia/comarca, respecto a la extensión total de la comarca; la unidad (1) señalaría que toda la tierra estaba bajo el dominio de los pequeños señorios, y cero que toda la tierra estaba bajo jurisdicción del monarca. Fuentes de Nf y Ex-f: El número de baronías y caballerías que había en cada distrito parroquial lo hemos obtenido de distintas fuentes: de las relaciones de feudos de la primera mitad del siglo xIV publicas por Ramis d'Ayreflor (1953, pp. 3-24) y Vich y Muntaner (1945, pp. 192-197) y la relación de feudos de 1389 en ARM, ERC-1145. Estas relaciones han sido contrastadas con las publicadas por Moll y Suau (1986) y Romero (1989), en las cuales figura una detallada relación de todos los dominios, su participación en el diezmo y la extensión de mucho de ellos.

de la tasa de sustracción con la fertilidad de la tierra y abundancia de agua, y la proximidad de los grandes mercados urbanos (Pollença, Inca, Ciutat), desigual en cada una de las parroquias, permitirían un rápido aumento de las densidades demográficas, y como han demostrado los estudios sobre la tenencia de la tierra, también una intensa fragmentación del parcelario, con un predominio de las pequeñas tenencias, que se arremolinaban en torno de un elevado número de villas y aldeas ${ }^{56}$.

Soto (1991, doc. $278,451,555)$ y López Bonet $(1989$, pp. 58-61), y en ejemplos documentales en los dominios del Conde de Ampurias (ARM, ECR-348, f. 70), o en los dominios del obispo de Gerona entre el 1289 y el 1330 (ADG, doc. 255, 356, 258, 278, 284, 283, 285).

so Las alquerías y rafales de estos lugares tenían, según el «Llibre del repartiment», una extensión media inferior a las de los distritos centrales y orientales de la isla, como ha puesto de relieve Poveda (1992, pp. 5-11; 1994, pp. 281-294). Las alquerías del Raïguer y los valles padecieron un proceso de establecimiento y subestablecimiento muy intenso desde el siglo Xw. Este proceso alcanzaría en muchas de ellas hasta 4 o 5 niveles enfitéuticos. Véanse los trabajos sobre las parroquias de Valldemossa, Inca y Bunyola en Soto (1990, 
Por el contrario, en las parroquias del centro y este de la isla ( $\mathrm{Pla}$, Migjorn y Llevant), los barones (conde de Empúries, Nunó Sanç, obispo de Girona, etc.) y el monarca habían creado una multitud de pequeños señoríos laicos, con una extensión media mayor que la que tenían en el este de la isla, y que se extendían sobre gran parte del término de las villas (cuadro 4). Esta situación aumentaba la competencia entre los señores, barones y caballeros, para atraer colonos a sus dominios, que tenían unas condiciones socio-ambientales menos favorables que las que se daban en las tierras del Raiguer o los valles de la Sierra ${ }^{57}$. Los estudios realizados y la documentación disponible sugieren que las diversas tentativas ensayadas por estos pequeños señores por acrecentar el número de familias asentadas en sus feudos no tuvieron éxito. ¿Qué factores explicarían las diferencias entre las elevadas densidades que se alcanzaron en las tierras donde solamente había un estrato feudal, compuesto por el rey o los barones, y las bajas densidades de las tierras que estaban bajo el estrato compuesto de barones y una multitud de pequeños señores? De hecho, la cuestión es por qué los señores no constituyeron villas tal como hizo el rey.

La formación de pueblas en Mallorca fue, efectivamente, una estrategia más bien real, y no señorial. La causa no fue tanto la falta de interés por parte de los señores como la imposibilidad de disponer de suficiente tierra, en unas de acceso más atractivas que las que ofrecía el monarca o los barones, como para dirigir y «ordenar» una redistribución del territorio. La documentación de la época muestra que la pequeña nobleza se encontro con una firme resistencia de los campesinos a caer bajo la jurisdicción señorial, y cómo los colonos optaron por consolidar un modelo de hábitat concentrado fuera de los límites jurisdiccionales de los señores feudales, generalmente en dominios reales ${ }^{58}$. Esta resistencia campesina

1991, 1999); sobre la parroquia de Pollença, Rodríguez (1985/6, 1994) y Argemí (1999); sobre Deià, Jaume Portella (1985/86, pp. 331-343), y sobre el distrito de Canarrossa ver Kirchner (1997).

${ }^{57}$ Por ctra parte, las cargas feudales - fundamentalmente la proporción que representaban los diezmos y tascas respecto de la cosecha bruta, y las tasas de mutación- eran similares en todas partes, mientras que la diferencia en los rendimientos de las cosechas difería mucho entre unos lugares y otros. Así, mientras el diezmo y la tasca podían ser soportables en las ricas tierras del Raiguer o en las parcelas que integraban el anillo de huertos y «suertes» que rodeaban las villas, estas mismas tasas resultaban extremadamente pesadas para las explotaciones que se extendían sobre las tierras delgadas y que disponian de escasos recursos hídricos. Ello impedía la fragmentación de la tierra y estimulaba la especialización pecuaria antes que la expansión cerealista. La distribución geográfica de las actividades agropecuarias en la isla durante el primer tercio del siglo XIV seguía, obviamente, estas pautas en López Bonet (1989) Soto (1996).

${ }^{58}$ Bernat y Serra (1997), Planas (1995, pp. 33-47). 
estaba encabezada por un estrato de aldeanos ricos que lideró el movimiento que conseguiría en 1315 el reconocimiento por el monarca de las universitats (concejos de las villas) y el Sindicat Forà (agrupación de los concejos rurales), que organizaban la política local y la representación de la población rural en la asamblea del reino ${ }^{59}$. Y, de otra parte, el despliegue de los bailes reales de las villas y la implantación de la jurisdicción real, que entorpecían el poder de las curias feudales y dificultarían los intentos señoriales de crear nuevas pueblas en sus dominios ${ }^{60}$. Parece probado que los campesinos preferían establecerse o continuar en la porción real que en los señoríos ${ }^{61}$.

Una interpretación idealizada de estos procesos, busca sus causas en el diferente «talante» de la estructura monárquica, estatal, y la de los señores, feudal. Sin embargo, la realidad era muy diferente. Las ordenaciones reales no fueron sino una forma de rentabilizar la porción real, el real patrimonio, mediante lo que en otro lugar hemos caracterizado como estrategia poblacionista. Lo que buscaba el rey era incrementar la renta que recibiría, y para ello planeó una ocupación más eficiente del territorio. Ello fue acompañado de una política de adquisición de tierras (recuperación del dominio útil, en definitiva) y de una necesaria política de reforma monetaria, que le permitiera manipular los créditos necesarios para tirar adelante el proceso ${ }^{62}$. Independientemente del éxito o del fracaso de estas pueblas, de su número y pervivencia, queda claro que casi todas ellas se cons-

${ }^{59}$ Desde finales del siglo xuI y a lo largo de la primera mitad del xN se estableció una sinergia entre el monarca y las comunidades campesinas, mientras éstas conseguían privilegios políticos (constitución de las universitats, representación en la asamblea del Reino), autonomía financiera y protección jurisdiccional del monarca, éste obtenía la aprobación de nuevos impuestos y subsidios al margen de los ingresos que le proporcionaba su patrimonio feudal. Véase Cateura (1982, pp. 181-203; 1999, pp. 288-291, 1998) y Planas (1995, pp. 50-71).

60 Los primeros trabajos sobre los intentos señoriales y reales de multiplicar el número de núcleos rurales en el centro y este de la isla fueron los de Alomar (1976) y López Bonet (1982, pp. 132-156). Para una reinterpretación de estas tentativas repobladoras en el sentido apuntado en el texto ver Bernat y Serra (1997) y sobre todo Mas (2000).

${ }^{61}$ Esto, según la verosímil hipótesis de Bernat y Serra (1997), tendría sus orígenes en la formación de las «pueblas» con una estructura defensiva en torno a espacios ensagrerats, que se habrían de interpretar como una de les respuestas de los colonos a los intentos señorializadores de los caballeros que tenían feudos en aquellos lugares. Véase también Mas (2000), Planas (1995, p. 45), Mas, Rosselló Bordoy y Rosselló Vaquer (1999, pp. 173-95).

${ }^{62}$ La política de adquisiciones hechas por el rey de Mallorca Jaume II a partir de 1298 , fecha de su reincorporación al frente de la administración mallorquina, contrasta con el escaso uso del derecho de la fadiga que se había realizado anteriormente. Dentro de la serie Novells del ARM, el primer registro que se conserva de estas características es de 1294, y, efectivamente, la actividad compradora por parte de los agentes del monarca se 
tituyeron en zonas de realengo, no obstante la existencia de algunos ejemplos de pueblas en zonas de señorío, como es el caso de la Palomera, en la porción del obispo de Barcelona, antes incluso del acuerdo de pariatge entre ambos. Los señores contaban con las mismas prerrogativas que el rey, en ese sentido, ya que la recuperación del dominio útil es una práctica feudal, no necesariamente confiscatoria, pero tenían mucho menos terreno y capacidad económica para llevarla a término ${ }^{63}$.

Como hemos dicho en los dominios reales, o en las grandes baronías incorporadas al patrimonio feudal del monarca, las reducciones de censos, las conmutaciones de tascas, o la reducción de la tasa de mutación (el laudemio) fueron frecuentes, y animaron el poblamiento de esas tierras. Esta estrategia del monarca se debe entender atendiendo a su estructura patrimonial. Una parte nada despreciable de sus ingresos derivaba de los monopolios comerciales y de los nuevos tributos fiscales que gravaban fundamentalmente el consumo y el tráfico mercantil de corta y larga distancia ${ }^{64}$. Estos sectores, fundamentalmente la economía urbana, estaban en expansión, y, por tanto, el monarca tenía a su alcance alternativas económicas al sector agrario que no podían usar los otros barones feudales ${ }^{65}$. Éstos, a su vez, si el monarca, el mayor señor feudal de la isla, optaba por reducir la tasa de sustracción, se veían también obligados a seguir su ejemplo, pues de otra manera los colonos podrían abandonar sus domi-

incrementa extraordinariamente a partir de la reincorporación al trono de Jaume $I I$, y se mantiene hasta el segundo decenio del siglo XIV (Mas, 2000; López Bonet, 1989, pp. 64-65).

${ }^{63}$ Los últimos estudios realizados confirman el fracaso de las políticas de poblamiento y creación de nuevas pueblas señoriales, solamente en los dominios reales se consolidaron los núcleos de población formados el siglo xIII y se crearon algunos de nuevos, véanse los recientes trabajos de Mas (2000).

${ }^{64} \mathrm{El}$ monarca fue gravando con nuevos impuestos las actividades comerciales y el consumo urbano desde mediados del siglo xiा (Cateura, 1997).

65 Tanto Riera Melis (1986, pp. 36-47, 63-69), como después Abulafia (1996, pp. 199-202) constataron el relativo fracaso en el desarrollo del sector primario. De hecho, el escaso desarrollo del sector agropecuario y la dependencia de la isla respecto de los mercados peninsulares o mediterráneos para su abastecimiento a principios del siglo xIV, fueron algunas de las debilidades que dificultaban la consolidación del reino de Mallorca como entidad independiente. En 1330 los ingresos que proporcionaban los dominios feudales del monarca se evaluaban en unas 20.000 libras, mientras que los ingresos fiscales que percibía el reino, y sobre los cuales el monarca obtenía subsidios y donaciones, alcanzaba ya las 30.000 libras. La mayoría de estos impuestos eran sisas, «ayudas» o «imposiciones» que gravaban el consumo y tráfico de los artículos de primera necesidad (harina, aceite, vino, tejidos, etc.), y el comercio portuario de la ciudad, véase Cateura $(1998,1999$, pp. 292-294). 
nios e instalarse en los del monarca ${ }^{66}$. Como hemos dicho, la prescripción de la servidumbre, o la generalización de las franquicias, impedía a los barones y señores feudales sujetar a los colonos en sus tierras.

Si la estrategia que dictaba el monarca condicionaba la política señorial en las baronías, ello era mucho más evidente en los pequeños dominios señoriales. La extensión de esta estrategia poblacionista a los pequeños dominios feudales, las caballerías, resultaba difícil. En parte esta dificultad derivaba de su escala. Las caballerías no disponían de grandes extensiones donde la reducción de la tasa de sustracción se pudiese compensar gracias a una multiplicación de las tenencias; además, para estos señoríos la reducción a la mitad de una de las principales fuentes de renta, el diezmo, impedía en estas circunstancias disminuir más otras cargas. Y, de otro lado, su localización, situados mayoritariamente en tierras alejadas de los núcleos urbanos y con una baja densidad de infraestructuras, dificultaba la atracción de colonos. Por tanto, no debe extrañarnos que la fragmentación de la tierra en las caballerías fuera escasa, tal como demuestran los inventarios de la primera mitad del siglo XIV ${ }^{67}$, que el señor se viera obligado a presionar mucho más a sus enfiteutas, que, por ejemplo, los barones o el monarca ${ }^{68}$. Por último, la venta de estos dominios por parte de algunos nobles en la década de 1240, y el intento de probar fortuna en la recién conquistada Valencia puede ser indicativo de las escasas perspectivas de incrementar la renta o la riqueza que tenían los poseedores de pequeños feudos, especialmente en el centro y este de la isla ${ }^{69}$.

${ }^{66}$ Como ha señalado Cateura (1997, pp. 67, 72, 76-78), en algunas baronías, como en la de Nunó Sanç, los niveles de sustracción eran superiores a los que tenían lugar en los dominios reales; no es de extrañar, pues, que tuvieran mayores dificultades en el poblamiento de sus tierras.

${ }^{67}$ Véanse las relaciones de enfiteutas de los dominios de Sa Verdera, Masnou, la Galera, etc., citados en el apartado segundo. En estos dominios la tierra estaba dividida entre unos pocos campesinos, entre media y una docena, y no se produjeron procesos de subestablecimientos, ni una acusada parcelación de la tierra en pequeños lotes, algo que sí sucedía alrededor de los pueblos o villorrios que se habían creado en los dominios reales o en las baronías.

${ }^{68}$ Los pequeños señores feudales durante esta etapa residían en sus dominios y seguian muy de cerca la captación de las rentas. Véase, por ejemplo, las exigencias del señor de la Galera a sus enfiteutas en los años inmediatamente anteriores y posteriores a la Peste de 1348. En diversas cartas advierte que sus enfiteutas no cultivaban toda la tierra que podían, con la fuerza de tiro disponible, y, por tanto, ello impedía que el señor obtuviese el máximo de renta por explotación, según la tierrá y ganado de labor de que disponía una explotación. Véase Obrador (1992, pp. 34-35).

69 Esto sucedió tanto en caballeros que poseían pequeños feudos o caballerías, como algunos señores más importantes (Cateura, 1997, pp. 76-78). 


\section{RECAPITULACIÓN: LAS ESTRUCTURAS FEUDALES Y EL DESARROLLO AGRARIO}

En este trabajo hemos mostrado que el feudalismo forjado desde arriba, dio como resultado una estructura señorial fuertemente jerarquizada, integrada por dos grandes estratos feudales relativamente homogéneos, que no se modificaría sustancialmente hasta la abolición del feudalismo ${ }^{70}$. En la cúspide se situaba el monarca, mientras que bajo su dominio eminente se extendían las baronías y caballerías, que tenían cuerpos territoriales relativamente compactos, $y$ en las cuales iban emparejados el dominio directo y el jurisdiccional. En segundo lugar, la fragmentación territorial del señorío era en la isla de Mallorca mucho menor que la que encontramos en los dominios señoriales catalanes ${ }^{71}$. Además, el poder jurisdiccional estaba fuertemente jerarquizado, y mediatizado por la jurisdicción real, de tal modo que los pequeños dominios de la nobleza mallorquina vieron recortada su capacidad de coerción sobre sus enfiteutas. La proscripción de la servidumbre, la limitación progresiva de la jurisdicción señorial a los pleitos civiles, y la competencia de las curias de los señoríos con otras jurisdicciones baronales, eclesiásticas, real o de las universidades de las villas, limitaba la eficacia de los tribunales señoriales.

En segundo lugar, hemos presentado la colonización feudal como un proceso conflictivo y lleno de dificultades de diversa índole: la domesticación de unos espacios agrarios creados por las sociedades andalusíes, la competencia entre los nobles para asegurarse una participación mayor en la distribución del poder y la renta, y la resistencia que oponían los campesinos a los señores feudales, y especialmente a los poseedores de caballerías. La combinación de estos factores y conflictos nos ha ayudado a comprender las desigualdades en las pautas de asentamiento en las diversas comarcas de la isla durante los siglos XIII y XIV. Y porque la población tendió a concentrarse en grandes núcleos urbanos, así como la escasa fragmentación de las tenencias en el centro y este de la isla, donde predominaban los grandes señoríos de la pequeña nobleza.

El éxito o fracaso relativos en las estrategias de colonización agraria que siguieron los dos grandes grupos nobiliarios también nos ha permitido caracterizar sus estructuras patrimoniales. Particularmente, queremos

70 Romero (1983), Moll y Suau (1986).

71 Esta fragmentación del feudalismo de la Cataluña del Nordeste era resultado de la formación endógena, como nos muestran los trabajos de Bonnassie (1979/81), Tó (1997,
1999 ). 
comentar uno de los rasgos más originales de este proceso: la pervivencia e importancia de la reserva señorial en los pequeños feudos mallorquines. A la vista de lo expuesto, quizás la explicación de la consolidación de esta estrategia no la deberíamos plantear en términos de una opción de carácter comercial, sino como una solución a los problemas que planteó el poblamiento rural y de los pequeños feudos en particular. Esta respuesta señorial debe vincularse también a la solución que se dio a la fuerza de trabajo. Así, la prescripción de la servidumbre y la expulsión de las comunidades rurales andalusíes, creó un vacío difícil de llenar en una etapa en que el crecimiento demográfico perdía fuerza y en que la atracción de las nuevas conquistas valencianas (1240) ofrecía mejores perspectivas tanto a los caballeros como a los posibles colonos. En este contexto, la esclavitud fue una solución atípica, pero no desconocida, y quizás la única alternativa posible para organizar la producción de las reservas señoriales y de las grandes explotaciones agrarias ${ }^{72}$.

El estudio de la formación del feudalismo en la isla de Mallorca, comparado con los otros modelos de la Corona de Aragón, presenta algunos contrastes que permiten iluminar aspectos más generales del desarrollo agrario bajomedieval. De una parte, parece que la difusión de la servidumbre o su ausencia jugaron un papel relevante en el diferente camino que siguieron los regímenes agrarios que se consolidaron en Cataluña y Mallorca, pero, paradójicamente, en un sentido completamente distinto del que a priori se le podría atribuir. En Cataluña la servidumbre consolidaría el mas como una unidad productiva y de exacción de rentas en el seno de los fragmentados señoríos de la Cataluña del noreste, y no como una forma jurídica de apropiación del trabajo para explotar las reservas señoriales ${ }^{73}$. Así, la otra cara de los malos usos y de los pesados derechos feudales que pesaban sobre las masías fue la consolidación de un campesinado relativamente acomodado, con unos derechos consolidados sobre el acceso y transmisión de la tierra ${ }^{74}$. En Mallorca, los privilegios que habían preservado a los colonos de la servidumbre no fueron, sin embargo,

72 Soto (2000) y Jover, Mas y Soto (2002).

${ }^{73}$ La función de la servidumbre en el régimen feudal catalán no era la misma que había tenido durante el feudalisrno franco o anglosajón de los siglos XI-Xm, o la que tendría después en la segunda servidumbre en la Europa Oriental, es decir, como una modalidad de sujetar y apropiarse del trabajo campesino para emplearlo en las grandes reservas señoriales para la producción comercial. Véase Brenner (1996, pp. 225-246), Freedman (1993) y Tó (1997, 1999).

${ }^{74}$ Una convincente explicación de las relaciones entre la imposición por los señores de la servidumbre, la consolidación de la primogenitura en el sistema de herencia campesina 
una ayuda sustancial para evitar la desposesión campesina que tuvo lugar en el siglo Xv, ni tampoco anulaban el resto de los derechos señoriales que pesaban sobre las comunidades y familias campesinas.

Los contrastes son también apreciables con aquellas zonas de formación exógena del feudalismo, en particular con respecto de Cataluña Nueva y el País Valenciano. En la primera, también se produjo un proceso de concentración de la población en pequeñas ciudades y villas, en torno a las cuales se desarrollaron importantes ruedos de agricultura intensiva e irrigada, rodeado de otro anillo de agricultura de secano ${ }^{75}$. En estas tierras se consolidó la pequeña explotación campesina como el eje de la sustracción señorial. Pero los señores feudales consiguieron el control sobre los amplios espacios despoblados que había entre los núcleos de población y agricultura campesina, sobre los cuales desarrollaron una ganadería extensiva. Si bien es verdad que estos espacios fueron objeto de constantes disputas entre los señores y las comunidades campesinas, también es cierto que la conservación por parte de los señores del dominio pleno sobre estas tierras les permitió controlar la colonización agraria de esos espacios en las etapas de crecimiento que tuvieron lugar en los siglos posteriores ${ }^{76}$. Algo que, como hemos visto, no podrian hacer los magnates en la isla, pues habían cedido toda la tierra en enfiteusis.

Si bien en la Cataluña occidental el sometimiento de los campesinos andalusíes no tendría un papel determinante en el desarrollo de aquella sociedad agraria ${ }^{77}$, en cambio, este factor marcó diferencias sustanciales entre la Cataluña occidental, Mallorca y el País Valenciano. La colonización feudal en esta última zona siguió un modelo parecido al del oeste catalán, pero introdujo una notable novedad respecto de aquél y la isla de Mallorca. A diferencia de Cataluña, donde la población andalusí despareció de la escena económica con relativa prontitud, o de Mallorca, donde fue esclavizada, en el País Valenciano una parte muy importante de las comunidades musulmanas preservaron su autonomía social, pero fueron sometidas a duras exacciones fiscales. Ello permitiría una base demográfica y económica a la colonización más amplia de la que los señores feudales habían tenido, diez o quince años antes, en la isla de Mallorca. Quizás ello les permitiría y del mas como unidad de explotación y sustracción de rentas, se encuentra en Tó (1997,
1999).

${ }_{75}$ Bolòs (1997, 1998, 1999) y Virgili (2001).

${ }^{76}$ Para la etapa medieval véase Bòlos $(1997,1998,1999)$ y Bertran (1997). Para los siglos XV a xvm, Feliu (1991), Vilar (1964) y Tello (1995)

${ }^{77}$ Virgili (2001). 
hacer frente a las dificultades que tenía el hecho de poblar rápidamente los nuevos territorios, en una etapa en que el ímpetu demográfico se adormecía y la frontera se ensanchaba, pero también marcaría una larga etapa de conflictos para someter a aquellas comunidades ${ }^{78}$.

La nueva sociedad feudal en la isla de Mallorca quedó definitivamente consolidada en torno a 1340. Si bien, la estructura jurídico-política había impedido a los señores tener un efectivo control sobre el trabajo campesino, pero permitió una relativamente rápida pero desigual colonización agraria de la isla. Además, el escaso poder coercitivo que tenían los feudos condicionaba las estrategias señoriales, especialmente por lo que respecta a incrementar su poder feudal: aumentar sus rentas, extender sus señoríos, o aumentar la opresión jurídica del campesinado. Pero, en cambio, algunos elementos de su estructura - señoríos compactos y pervivencia de la reserva señorial - dejaban las puertas abiertas a determinadas modalidades de desarrollo agrario. Ciertamente, la organización del espacio agrario feudal que se había consolidado, en particular la escasa fragmentación de las alquerías en el centro y este de la isla o en las sierras, ofrecería a los poseedores del dominio útil (grandes enfiteutas) o pleno (la pequeña nobleza feudal) interesantes oportunidades para recomponer su maltrecha economía después de la depresión de la segunda mitad del siglo xIv: la cría extensiva de ganado señalaría la vía a la salida de la crisis de ingresos que padecía la nobleza. Así pues, en el siglo xv la fortuna sonreiría a aquellos, señores feudales o terratenientes enfiteutas, que poseían grandes extensiones de tierras en aquellas zonas (centro y este de la isla, y las zonas más elevadas de la Sierra de Tramontana) donde la resistencia campesina había contribuido al fracaso del poblamiento feudal del siglo XIII ${ }^{79}$.

\section{BIBLIOGRAFÍA}

AAVV (2000): Il feudalesimo nell'alto medioevo. XIVII Settimana di Studio del centro italiano di studi sull'alto medioevo de Spoleto, Spoletto.

ABUlaFiA, D. (1996): Un emporio mediterráneo. El reino catalán de Mallorca, Barcelona, Omega.

Alomar, G., y Rosselló, R. (1989): Història de Muro. Volum II, Mallorca, Ajuntament de Muro.

Alomar, G. (1976): Urbanismo regional en la Edad Media: las «Ordinacions» de Jaime II (1300) en el reino de Mallorca, Barcelona, Gustavo Gili.

${ }_{78}$ Torró (2000) y Furió (1997b).

79 Sobre la formación de las grandes haciendas agrarias en la Mallorca del siglo XV véase Jover (1994, 1997). 
Argemí, M. (1997): «A la recerca de la lògica dels assentaments andalusins al guz de Yartan (Mayûra)». Treball de recerca inédit, UAB.

- (1999): A les vores dels torrents. Una prospecció dels assentaments pagesos andalusins de Pollença, Pollença, Anuari, núm. 6 (desembre).

BARCELO CRESPÍ, M. (1979-1980): «Algunes anotacions sobre el sistema defensiu de Mallorca: els cavalls armats», Mayurqa, núm. 19, pp. 97-111.

- (1988): «Aspectes agraris d'un nucli urbà: Ciutat de Mallorca a la Baixa Edat Mitjana, BSAL, núm. 44, pp. 195-202.

BARCELO, Alfons (1981): Reproducción económica y modos de producción, Barcelona, Serbal.

Barceló, Miquel (1984): Sobre Mayûrqa, Palma de Mallorca, Quaderns de Ca la Gran Cristiana, núm. 2.

- (1989): «El diseño de espacios irrigados en al-Andalus: un enunciado de principios generales», El agua en las zonas áridas. Arqueologia e Historia. I Coloquio de Historia y medio físico, vol. I, Almería, pp. 15-41.

- (1995): «Saber lo que es un espacio hidráulico y lo que no es o al-Andalus y los feudales», en J. A. GonzÁlez y A. MalpiCA (ed.), El agua. Mitos, ritos y realidades, Granada, Anthropos, pp. 240-254.

BARCEló, Mique!, et alia (1988): Arqueología medieval. En las afueras del medievalismo, Barcelona, Crítica.

BarCEló, M., y KIRCHNER, H. (1995): Terra de Falanis (Felanitx quan no bo era), Palma, Ajuntament de Felanitx/Universitat de les Illes Balears.

BARCELO, M., y TouberT, P. (dir.) (1998): «L'incastellamento», Actes des reconcontres de Gérone (26-27 novembre 1992) et de Rome (5-7 mai 1994), Roma.

BartletT, R. (1994): The making of Europe. Colonization and Cultural Change 950-1350, Londres, Penguin.

BATES, D. (2000): «England and the "feudal revolution"», en Il feudalesimo nell'alto medioevo. XLVII Settimana di Studio del centro italiano di studi sull'alto medioevo de Spoleto, pp. 611-646.

BATET, C., y Soro, R. (1997): «Las donaciones a censo y los establecimientos como estrategia señorial (patrimonio Sentmenat, siglos $\mathrm{x}-\mathrm{xV}$ )», VII Congreso de Historia Agraria, Salamanca, pp. 227-243.

BATET, C. (1996): Castells termenats i estratègia d'expansió comtal. La Marca de Barcelona als segles $X-X I$, St. Sadurní d'Anoia, Institut d'Estudis Penedesencs.

- (2001): L'aigua conquerida. Hidraulisme feudal en terres de conquesta: alguns exemples de la Catalunya nova i de Mallorca, tesis doctoral inédita, UAB.

BERnAT, M. (1997): «Feudalisme i infraestructura artesanal. De Madîna Mayûrqa a Ciutat de Mallorca», BSAL, núm. 53, pp. 27-70.

- (2000): «Els inicis dels oficis de menestrals: els paraires i els teixidors de llana (Ciutat de Mallorca, segle XIII», en Lluís VIRós, Organització del treball preindustrial: confraries $i$ oficis, Barcelona, Publicacions de l'Abadia de Montserrat.

BERNAT, M., y SERRA, J. (1997): «Espacios sagtados y comunidades rurales: algunas hipótesis sobre colonización y sagreras en Mallorca siglos XII-XIV», Boletín Arqueológico Medieval, núm. 11, pp. 157-206.

BERTRAN, P. (1997): «Ordes militars i organització del territori: els hiospitalers durant la baixa edat mitjana», Territori $i$ Societat a l'Edat Mijana, núm. I, pp. 209-234. 
Bisson, J. (1977): L'bomme et la terre aux îles Baléares, Aix-en-Provence, Edisud. BISSON, T. N. (1984): «El feudalismo en la Cataluña del siglo xI», en R. PASTOR (ed.) et alia (1984), Estructuras feudales y feudalismo en el mundo mediterráneo, Barcelona, Crítica, pp. 66-91.

BLOCH, M. [1931 (1978)]: La historia rural francesa. Caracteres originales, Barcelona, Crítica.

- (1967): Seignerurie française et manoir anglais, Paris, Cahiers des Annales.

BoIs, G. (1989): La mutation de l'an mil. Lournand, village mâconnaise de l'Antiquité au Féodalisme, París (ed. española de 1991, Barcelona, Crítica).

Bolòs, J. (1997): «El territori i els seus límits. El poble, la parròquia i el castell a l'edat mitjana», Territori $i$ Societat a l'Edat Mitjana, núm. I, pp. 41-82.

- (1998): «Els pobles de Catalunya a l'edat mitjana. Aportació a l'estudi de la morfogènisi dels llocs de poblament», Territori $i$ Societat a l'Edat Mitjana, núm. II, pp. 69-138.

- (1999): «Dominis monàstics i organització del territori a l'edat mitjana», Territori $i$ Societat a l'Edat Mitjana, núm. III, pp. 127-165.

Bonnassie, P. (1979-1981): Catalunya mil anys enrera, 2 vols, Barcelona, Edicions 62.

- (1984): «Del Ródano a Galicia: génesis y modalidades del régimen feudal», en R. PASTOR (ed.) et alia (1984), Estructuras feudales y feudalismo en el mundo mediterráneo, Barcelona, Crítica, pp. 21-65.

- (2000): «Sur la genése de la feodalité catalane. Nouvelles approches», en Il feudalesimo nell'alto medioevo. XLVII Settimana di Studio del centro italiano di studi sull'alto medioevo de Spoleto, pp. 569-606.

BRENNER, R. (1996): «Auges y declives de la servidumbre en Europa durante la Edad Media y la Edad Moderna», Hispania, núm. 192.

BRESC, H. (1997): «El impacto de la conquista normanda sobre la agricultura siciliana: del islam al latifundio», en J. MorIlla, J. Gómez-PANTos y P. CRÉssier (eds.), Impactos exteriores sobre el mundo rural mediterráneo, Madrid, pp. 175-201.

Capó Villalonga, J. (1985): Història de Lloseta, t. I, Palma.

Carbonero, M. A. (1992): L'espai de l'aigua. Petita bidràulica tradicional a Mallorca, Palma de Mallorca, Institut d'Estudis Baleàrics.

Cateura, P. (1982a): Política y Finanzas del Reino de Mallorca bajo Pedro IV de Aragón, Palma de Mallorca, Institut d'Estudis Baleàrics.

- (1982b): «Mallorca y la política patrimonial de la monarquía (siglo xIII y primera mitad del XIV», Estudis Baleàrics, núm. 6, pp. 79-130.

- (1984): Sociedad, jerarquía y poder en la Mallorca medieval, Palma, Institut d'Estudis Baleàrics.

- (1985): «Mallorca en la segona meitat del segle xun (Aspectes polítics i financers fins a 1276», Estudis Balearics, núm. 17, pp. 57-86.

- (1986): «Mallorca a la segona meitat del segle xuI (Aspectes polítics i financers fins a 1276), Estudis Baleàrics, núm. 17, pp. 57-86.

- (1988): «La repoblación nobiliaria de Mallorca por Nunó Sans», Actes du XIII Congrès d'Histoire de la Couronne d'Aragon, Montpeller, pp. 99-114.

- (1992): «Fiscalidad real y municipal en la Mallorca del siglo XIV», Anuario de Estudios Medievales, núm. 22. 
- (1997): «La cuentas de la colonización feudal (Mallorca, 1231-1245)», En la España medieval, núm. 20, Madrid, pp. 57-143.

- (1998): El regne esvait: desenvolupament econòmic, subordinació política, expansió fiscal (Mallorca, 1300-1335), Palma, El Tall.

- (1999): «La "Ciutat de mallorques" y las villas mallorquinas: presión fiscal y conflictos sociales», en DDAA, Finanzas y fiscalidad Municipal, Madrid, CSIC.

Colom, (1978): Biogeografía de las islas Baleares, Palma, Consell de Mallorca.

COMNINEL, (2000): «English Feudalism and the Origins of Capitalism», Journal of Peasant Studies, vol. 27, núm. 4, pp. 1-53.

Congost, R., y Tò, Ll. (eds.) (1999): Homes, masos, història: la Catalunya del Nord-Est, segles XI-XX, Girona, Publicacions de l'Abadia de Montserrat.

FeLIU, G. (1991):, El funcionament del règim senyorial a l'Edat Moderna. L'exemple del Pla d'Urgell, Lleida, Institut d'Estudis Ilerdencs.

- (1999a): «La vida económica», en Historia de España Menéndez Pidal, t. VI, vol. 2, Madrid, pp. 651-697.

- (1999b): «La pre-Cataluña», en Historia de España Menéndez Pidal, t. VII, vol. 2, Madrid, pp. 364.392

FerRer MALlOL, M. T. (1970-1971): «El patrimoni reial i la recuperació dels senyorius jurisdiccionals en els estats catalano-aragonesos a la fi del segle XIN», Anuario de Estudios Medievales, núm. 7, pp. 351-491.

Fontanals, R. (1984): Un plànol de la sèquia de la vila del segle XIV (Ciutat de Mallorca), Palma, El Tall.

FreEdMAN, P. (1988): Assaig d'bistòria de la pagesia catalana (segles XI-XV), Barcelona, Edicions 62.

- (1993): Els orígens de la servitud pagesa a la Catalunya medieval, Vic, Eumo.

FuRIÓ, A. (1997a): «Senyors i senyories al país valencià al final de l'edat mitjana», Revista d'Història Medieval, núm. 8, Valencia, pp. 109-151.

- (1997b): «Organització del territori i canvi social al País Valencià després de la conquesta cristiana», Territori $i$ Societat a l'Edat Mitjana, núm. I, pp. 131-166.

García de CorTÁzAR, J. A. (2000): «Estructuras sociales y relaciones de poder en León y Castilla en los siglos vil a XII: la formación de una sociedad feudal», en Il feudalesimo nell'alto medioevo. XLVII Settimana di Studio del centro italiano di studi sull'alto medioevo de Spoleto, pp. 497-563.

Gili, A. (2000): De Santa Maria de Bellver a Sant Llorenç des Cardassar, Barcelona, Publicacions de l'Abadia de Montserrat.

GuICHARD, P. (1976): Al-Andalus. Estructura antropológica de una sociedad islámica en Occidente, Barcelona, Barral.

GuinOt, E. (1997): «La creació de les senyories en una societat feudal de frontera: el regne de València (segles xum-XIv)», Revista d'Història Medieval, núm. 8, Valencia, pp. 79-108.

JOVER, G. (1994): «La crisi tardomedieval i el desenvolupament d'una ramaderia senyorial. Mallorca, segles XIV-XVI», Butlleti de la Societat Catalana d'Estudis Històrics, vol. V, Barcelona, pp. 81-100.

- (1997): Societat rural i desenvolupament econòmic a Mallorca. Feudalisme, latifundi i pagesia, 1500-1800, tesi de doctorat inèdita, Departament d'Història i Institucions Econòmiques, Universitat de Barcelona. 
Jover, G., y Soto, R. (1997): «Els dominis feudals a la Mallorca baixmedieval (segles XIII-XVI», Revista d'Història Medieval, núm. 8, València, pp. 217-274.

- (en prensa): «De la Agricultura Andalusí a la feudal: cuna ruptura agroecológica?», en Alberto SABIO (ed.), La Construcción del paisaje rural en España y Cuba, Madrid, Prensas Universitarias de la Universidad de Zaragoza-Libros de la Catarata, Madrid

Jover, G.; MAS, A., y SoTO, R. (2002): «Feus, reserva senyorial i esclavitud. Mallorca a la segona meitat del segle XIV», en C. MiR y E. VICEDo (eds.), Control social $i$ quotidianitat. Terceres jomades sobre sistemes agraris, organització social i poder local als paisos catalans, Lleida, Institut d'Estudis Ilerdencs, pp. 141-180.

KIRCHNER, H. (1997): La construcció de l'espai pagès a Mayûrqa: les valls de Bunyola, Orient, Coanegra i Alaró, Palma, Universitat de les Illes Balears.

LEwTs, A. R. (1958): The Northern Seas, Princeton University Press.

LÓPEZ BONET, J. F. (1982): «Les ordinacions de Jaume II per a establiment de noves viles a Mallorca (1300)», Estudis Baleàrics, núm. 6, pp. 131-156.

- (1986): «Comunidad y Corona: el precio de servir. (Las cargas sobre el consumo en el siglo XIV en Mallorca)», Monogràfic de la revista Estudis d'Història Econòmica.

- (1989): La riquesa de Mallorca al s. XIV (Evolució $i$ tendències econòmiques), Palma.

- (1991): «La pràctica fiscal a la Mallorca de la baixa edat mitjana (segles XII-XIV), Randa, núm. 21.

- (1995): «La diversificación fiscal, pauta del desarrollo urbano en la "Ciudad e Isla" de Mallorca, Actas del Encuentro de estudios sobre actividad económica $y$ desarrollo urbano en los siglos XIV y XV», Istituto Italiano de Cultura de Barcelona, pp. 27-83.

- (1998): «Els pariatges del rei Sanç», en P. Cateura (ed.) (1998), XVIII Jornades d'estudis bistòrics Locals. El Regne Privatiu de Mallorca, Palma de Mallorca, pp. 101-132.

Mallorqui, E. (1997): «Homes, viles i masos (Cruïles, 1319)», en Rosa Congost y Lluís Tó (eds.), Homes, Masos Història. La Catalunya del Nord-est (segles XI-XX), Barcelona, Abadia de Montserrat.

MAS, A. (1994): «El procés repoblador a Mallorca durant la primera meitat del segle XIv. Una aportació al seu estudi», Bolletí de la Societat Arqueològica Luliana (BSAL), núm. 50, pp. 167-198.

- (2000): «Endeutament pagès $i$ alienació de la terra a Mallorca durant la segona meitat del segle xv. L'exemple del terme de Maria de la Salut», I Jomades d'Història Local de Maria de la Salut.

Mas, A.; Rosselló, G., y Rosselló, R. (1999): Història d'Alcúdia. De l'època islàmica a la Germania, Alcúdia, Ajuntament d'Alcúdia.

Miralles Montserrat, J. (1988): «Prenoms dels homes d'armes mallorquins del 1359», en Manent y J. VenY, Miscel lània bomenatge a Enric Moreu-Rey, vol. II, Barcelona, pp. 445-463.

MOLl, I., y SUAU, J. (1986): «Canvis i permanència de les institucions senyorials a Mallorca durant el segle XIX», a DDAA, Terra, treball $i$ propietat. Classes agràries $i$ règim senyorial als Paisos Caialans, Barcelona, Crítica, pp. 66-106. 
MonTANER, P. (1986): «Les cavalleries mallorquines (segles XII-XvII), en DDAA, Terra, treball $i$ propietat. Classes agràries $i$ règim senyorial als Països Catalans, Barcelona, pp. 42-65.

Mora, P., y Adrinal, Ll. (1982): Diplomatari del monestir de Santa Maria la Real de Mallorca (1232-1360), Palma.

Mut, A, y Rosselió, G. (1993): La remembrança de Nunyo Sanç. Una relació de les seves propietats a la ruralia de Mallorca, Palma, Museu de Mallorca.

OBRADOR, J. (1992): La cavalleria de la Galera, Felanitx.

PASTOR, R. (ed.), et alia (1984): Estructuras feudales y feudalismo en el mundo mediterráneo, Barcelona, Crítica.

Pérez, P. (1994): «El feu de Guillem de Torrella i la cavalleria de Guillem Sacosta», $B S A L$, núm. 50 , pp. 69-96.

Piferrer, P., y Quadrado, J. M. (1888): Islas Baleares, Palma de Mallorca.

Planas Rosselló, A. (1995): El Sindicat de Fora. Corporación representativa de las villas de Mallorca (1315-1834), Palma de Mallorca, Miquel Font.

Pons-Guri, J. M. (1985-1986): «Entre l'emfiteusi i el feudalisme (Els reculls de dret gironins). La formació i expansió del feudalisme català», Actes del Col.loqui organtizat pel Col.legi universitari de Girona (8-11 de gener de 1985), Estudi General, núms. 5-6, pp. 411-418.

Portella, J. (1985-86): «La colonització feudal de Mallorca: els primers establiments de l'alqueria Deià 81232-1245)», La formació $i$ expansió del feudalisme català, Actes del Col.loqui organtizat pel Col.legi universitari de Girona (8-11 de gener de 1985), Estudi General, núms. 5-6, Girona, pp. 331-343.

- (1994): «Les baronies i cavalleries de Mallorca dels segles XII i xIV. In feudum ad consuetudinem Barchinone», Afers, núm. 18, pp. 427-441.

- (1998): «Cómo se exporta el feudalismo: el caso de Mallorca», L'Incastellamento, Actes des reconcontres de Gérone (26-27 novembre 1992) et de Rome (5-7 mai 1994), sous la direction de M. Barceló et P. Toubert, Roma, pp. 85-98.

PovedA, A. (1985-1986): «Algunes hipòtesis sobre l'economia del juz' e Jijnû-Bitra a Mayûrqa, segons la toponímia àrab berber», La formació $i$ expansió del feudalisme català. Actes del Col.loqui Universitari de Girona, pp. 265-273.

- (1992): «Mayûrqa, un espacio agrario de alquerías y rahales», Estudis dHistòria Econòmica, I, pp. 5-11.

Quadrado, J. M. (1894): Privilegios y franquicias de Mallorca, cédulas, capitulos, estatutos, órdenes y pragmáticas otorgadas por los Reyes de Mallorca, de Aragón $y$ de España desde el siglo XII basta el fin del XVII, Palma de Mallorca.

Ramis D'Ayreflor Sureda, J. (1933): Antigues possessions d'Artà, Palma de Mallorca, Gráficas Miramar.

- (1952): Memorias medievales de una villa mallorquina, Mallorca, Gráficas Miramar.

RAMIS D'AYREFLOR, J. (1935): Estament militar $i$ proboms amb bonors de cavallers de Mallorca de mitian segle XIV (1332-1362), Palma.

Riera FraU, M. (1993): Evolució urbana i topogrâfica de Madîna Mayûrqa, Palma, Museo de Mallorca.

Riera Melis, A. (1986): La corona de Aragón y el Reino de Mallorca en el primer cuarto del siglo XIV. I-Las repercusiones Arancelarias de la Autonomía Balear (1298-1311), Madrid-Barcelona. 
Rodríguez, A. (1985-86): «Conquesta i feudalització: el cas de Pollença, Mallorca (1298-1304)», La formació $i$ expansió del feudalisme català, Actes del Col.loqui organtizat pel Col.legi universitari de Girona (8-11 de gener de 1985), pp. 371-387.

- (1994): «Dos moments en la colonització feudal del Nord-oest de Mallorca (Pollença, 1298/1304-1319/1325)», Afers, 18.

RoMEro, J. (1983): «Notas comparativas entre el señorío valenciano y los territorios de la antigua Corona de Aragón. Dos elementos básicos: la ausencia de población morisca en Cataluña y las islas y la peculiaridad del modelo insular», Estudis, núm. 10.

Rosselló VAQuer, R. (1989): «El pla de sant Jordi. Notes històriques (segles XIII-XIV), BSAL, núm. 45, pp. 91-104.

Rosselló Verger, V. M. (1964): Mallorca. El sur y el sureste (Municipios de Llucmajor, Campos, Ses Salines, Santanyi, Felanitx y Manacor), Palma de Mallorca, Cámara oficial de industria, comercio y navegación.

- (1959): «La huerta de Levante en Palma de Mallorca», Estudios Geográficos, núm. 77, Madrid, pp. 533-557.

SALRACH, J. M. (1999): «La pre-Cataluña: los grupos sociales» y «El régimen político condal», en Historia de España Menéndez Pidal, vol. VII, Madrid, pp. 395-426 у $576-612$.

Santamarí, A. (1990): Ejecutoria del reino de Mallorca, Ayuntamiento de Palma de Mallorca, Palma.

SASTRE, J. (1990): «La producción agraria de Inca, Valldemossa, Llucmajor y Montuiri según la declaración del diezmo de $1310 »$, XIII Congrés d'Història de la Corona d'Aragó, Palma.

Sevillano Colom, F. (1974): «La demografía de Mallorca a través del impuesto del morabatí, siglos XIV-XVI», BSAL, XXXIV, pp. 233-272.

Soto, R. (1979): «Mesquites urbanes i mesquites rurals a Mayûra (Estudi documental i problemes d'interpretació)», BSAL, núm. XXXVII, pp. 113-135.

- (1990): «"Repartiment" $\mathrm{i}$ "repartiments". L'ordenació d'un espai de colonització feudal a la Mallorca del segle xum», De Al-Andalus a la sociedad feudal: los repartimientos bajomedievales, Anuario de Estudios Medievales, núm. 25, pp. 1-51.

- (1991): L'ordenació de l'espai $i$ les relacions socials a Mallorca en el segle XIII (1229-1301), tesi de doctorat inèdita, Universitat Autònoma de Barcelona, Bellaterra.

- (1992): «Ovelles, vaques, porcs $\mathrm{i}$ eclesiàstics (Algunes consideracions sobre la ramaderia balear a l'Edat Mitjana, segles XI-XIV», Estudis d'Història Econòmica, 1992/1, pp. 13-29.

- (1994a): «La situació dels andalusins (musulmans i batejats) a Mallorca després de la conquesta catalana de 1230», Mélanges de la Casa de Velázquez, XXX/1, pp. 167-206.

- (1994b): «La porció de Nunó Sanç. Repartiment i repoblació de les terres del Sud-Est de Mallorca», Afers, núm. 18, pp. 347-365.

- (1996): Conquesta, repartiment i colonització de Mallorca durant el segle xuI. Un estat de la qüestió, Anuario de Estudios Medievales, 26/2, pp. 605-646.

- (1997): «Patrimoni reial i transformacions agràries a Mallorca en el segle XII», Col.loqui Corona, municipis i fiscalitai a la Baixa Edat Mitjana, Lleida, noviembre de 1995, pp. 555-573. 
- (1999): «Colonització i diferenciació pagesa a la Mallorca del segle xII», Doctor Jordi Nadal. La industrialització $i$ el desenvolupament econòmic d'Espanya, vol. I, Universitat de Barcelona, pp. 375-401.

- (2000): «¿Una oferta sin demanda? La esclavitud agraria en Mallorca antes de la peste negra», Historia Agraria, núm. 21, pp. 11-31.

Tello, E. (1995): Cervera $i$ la Segarra al segle XVIII, Lleida, Pagès.

- (1999): «La formación histórica de los paisajes agrarios mediterráneos: una aproximación ecoevolutiva», Historia Agraria, núm. 19, pp. 195-214.

Tó, Ll. (1997): Familia i bereu a la Catalunya nord-oriental (segles X-XII), Barcelona, Abadia de Montserrat.

- (1999): «El nom dels masos (el domini de Santa Maria de Vilabertran en els segles XI-XIII)», en Rosa Congost y Lluís Tó (eds.), Homes, Masos Història. La Catalunya del Nord-est (segles XI-XX), Barcelona, Abadia de Montserrat, pp. 23-42.

TORRó, J. (1999): El naixement d'una colònia. Dominació i resistència a la frontera valenciana (1239-1276), Valencia, Universitat de Valencia.

- (2000): «Jerusalem ou Valence? Les débuts de l'expansion européenne et la première colonie d'Occident», Annales, Histoire, Sciences Sociales, 55-5.

TOUBERT, P. (1973): Les structures du Latium médieval. Le Latium mèridional et la Sabine du IX siècle à la fin du XIIe siècle, Roma.

TRILLO, C. (1999): «El paisaje vegetal en la Granada islámica y sus transformaciones tras la conquista castellana», Revista de Historia Agraria, núm. 17, pp. 131-152.

Urgell, R. (1990): «Proceso entre Sancho de Mallorca y la Iglesia de Tarragona por derechos de jurisdicción en Ibiza y Formentera», pp. 15-32 dins XIII Congrés d'Història de la Corona d'Aragó. Comunicacions I (primera part), Institut d'Estudis Baleàrics, Palma de Mallorca.

Vich, J., y Muntaner, J. (1945): Documenta Regni Maioricarum, Moll Editorial, Palma.

VILAR, P. (1964): Catalunya dins l'Espanya moderna, vol. I, Barcelona, Edicions 62.

VIRGILI, A. (2001): «Ad detrimendum Hispaniae... La conquesta de Turtusa y la formació de la societat feudal (1148-1200), Barcelona, Publicacions de la Universitat de Valencia-Universitat Autònoma de Barcelona.

WICKHAM, Ch. (1984): «The other transition from the Ancient World to Feudalism», Past and Present, núm. 103, pp. 3-36.

- (2000): «Le forme del feudalesimo», en Il feudalesimo nell'alto medioevo. XLVII Settimana di Studio del centro italiano di studi sull'alto medioevo de Spoleto, pp. 15-46.

\section{ABREVIATURAS DE LA DOCUMENTACIÓN CITADA}

ARM Archivo del Regne de Mallorca.

A Real Audiencia.

PN Protocolos notariales.

AGT Archivo de la casa Torrella.

ACM Archivo Capitular de Mallorca. 
ADM Archivo Diocesano de Mallorca.

ACG Archivo Capitular de Girona.

ADG Archivo Diocesano de Girona.

AHG Archivo Histórico de Girona.

CHCA Congreso de Historia de la Corona de Aragón.

BOCCIN Boletín de la Cámara Oficial de Comercio Industria y Navegación.

BSAL Butlleti de la Societat Arqueologica Lul.liana 